\title{
A Strategic Planning Methodology for the Multimodal Transportation Systems: A Case Study from Turkey
}

\author{
Umut R. Tuzkaya, ${ }^{1}$ Semih Onut, ${ }^{1}$ and Gulfem Tuzkaya ${ }^{2}$ \\ ${ }^{1}$ Department of Industrial Engineering, Yildiz Technical University, Barbaros Street, Yildiz, 34349 Istanbul, Turkey \\ ${ }^{2}$ Department of Industrial Engineering, Marmara University, Göztepe, 34722 Istanbul, Turkey \\ Correspondence should be addressed to Umut R. Tuzkaya; tuzkaya@yildiz.edu.tr
}

Received 7 March 2014; Revised 30 May 2014; Accepted 3 June 2014; Published 19 August 2014

Academic Editor: Chong Lin

Copyright ( 2014 Umut R. Tuzkaya et al. This is an open access article distributed under the Creative Commons Attribution License, which permits unrestricted use, distribution, and reproduction in any medium, provided the original work is properly cited.

\begin{abstract}
Transportation costs have an important effect on companies' competition capability in various sectors. To realize a positive effect, transportation industry should provide some specific performance criteria related with the economical efficiency and service quality. Also an increase in this performance degree depends on the obtaining optimum results of using the logistical resources in a convenient manner by the specialized logistics service providers. In this study, considering the effects of transportation modes on constituting a methodology that is interested in a strategic subject like constructing a transportation network is emphasized. In the process of selecting the most convenient transportation modes, all the required criteria are determined considering the related literature and the opinions of the experts. Then the analytical network process methodology is used to solve this selection problem. The close relationship between the transportation modes that will be used among the points in the network and the points that will be used for short storages and transshipment activities is considered. And the analytical network process is again used to select the most convenient ones among the alternative port locations. After decision making on these two important points, optimizing the freight flow among the supply chain by choosing the right transportation modes at each stage is aimed. To realize that optimization, the aims of decision makers from different levels or from different functional areas are satisfied by using the multilevel programming technique. Finally, the proposed methodology is applied on a transportation project of a logistic service provider, which gives service in a multimodal, multicommodity, multilevel and multiechelon transportation network.
\end{abstract}

\section{Introduction}

Over the past years, global supply chain management is becoming an important issue for many businesses. Increased globalization and offshore sourcing have created a massive increase in the complexity of supply lines and transportation networks. This has led firms to give more importance to the transportation and distribution functions and its associated long-term design decisions [1]. These competitive pressures and growth in globalization have motivated both practitioner and academic interest in transportation/distribution network design and transportation road/mode combinations.

Considering the above mentioned context, logistics service providers (LSP) might consider the effects of transportation modes on their strategic plans about transportation activities. When the current literature on transportation systems is examined, large body of the studies can be found on transportation modes and multimodal transportation. While for a certain part of these studies, operations are investigated from the perspective of LSP, the rest of the studies are realized with the consideration of different decision makers' perspectives such as suppliers, transportation operators, network operators, and terminal operators [2]. Investigated decision making areas about multimodal transportation consist of various problems such as facility location selection, decisions about operations of transshipment terminals, distribution and supply phases, and distance transportation phase. Another research area is the transportation networks and selection of the convenient routes and transportation modes of transportation operators. Various solution procedures are deterministic, stochastic, heuristic, simulation techniques, and so forth. Since there is a vast amount of articles on 
the above mentioned literature, we only reviewed the articles belonging to freight transportation network design, freight transport operations, intermodal freight transportation, and multimodal freight transportation issues that were published in the last four years.

Rieksts and Ventura [3] analyzed theoretical inventory models with constant demand rate and two transportation modes. The authors considered different transportation options, namely, truckloads with fixed costs, a package delivery carrier with a constant cost per unit, and a combination of both modes simultaneously. In another work published by Chang [4], the international intermodal routing problem was formulated as a multiobjective multimodal multicommodity flow problem. The objectives of this paper were to develop a mathematical model encompassing all three essential characteristics and to propose an algorithm that can effectively provide answers to the model. Since the problem was NPhard, the authors proposed a heuristic algorithm based on relaxation and decomposition techniques. Macharis and Pekin [5] developed a geographic information system based location analysis model for Belgian intermodal terminals and used simulations of this model to assess different policy measures in Belgium. Another study by Andersen et al. [6] addressed the service network design with asset management problem, which integrates asset management considerations into service network design models for consolidation-based freight carriers. They presented four alternate formulations of a model for service network design with asset management by combining arc and cycle design variables with arc and path flow variables over a time-space network. In another study, a system-optimized logistics network design problem was formulated as a bilevel mathematical program [7]. At the upper level a set of decision variables of interests was considered, and at the lower level a user equilibrium traffic assignment problem with marginal costs was solved. Dias et al. [8] were concerned with the design and development of a functional framework for sea mode integration in European automotive supply chain management when considering outbound distribution. An analytical framework for planning rail-truck intermodal transportation of dangerous goods was presented by Verma and Verter [9]. A biobjective optimization model to plan and manage intermodal shipments was developed. An iterative decomposition based solution methodology was also provided. Another study published by Pishvaee et al. [10] focused on the issue of integrated multiobjective, multistage forward/reverse logistics network design including production, distribution, collection/inspection, recovery, and disposal facilities with multiple capacity levels. A biobjective mixed integer programming formulation was developed to minimize the total costs and maximize the responsiveness of a logistics network. To find the set of nondominated solutions, a multiobjective memetic algorithm was also developed.

Bock [11] proposed a real-time approach for freight forwarder transportation networks. For the first time, this model integrates multimodal transport chains and multiple transshipments. Furthermore, the use of transportation hubs and external services that result from cooperative agreements was also considered. Another approach that synchronizes each timing point found between a supplier and a buyer in the serial supply chain with one in two timing points to make material flow more efficient and agile was presented by Jung and Lee [12]. Some heuristic algorithms based on simulated annealing and a genetic algorithm were also suggested to obtain a good solution in a reasonable time. Apivatanagul and Regan [13] developed a network design model for long haul freight movements, which were represented by relationships between shippers and carriers. Another study by Ishfaq and Sox [14] described an interregional, hub based, intermodal logistics network operated by a logistics service provider. A tabu search metaheuristic was used to solve a mathematical optimization model that extends the $\mathrm{p}$ hub median model for interacting hub location-allocation problems to the domain of intermodal logistics. Dotoli et al. [15] addressed the management of intermodal transport system at the operational level focusing on the impact of the information and communication technologies on the management and control of the intermodal chain. Intermodal transport system was regarded as discrete event systems and was modeled in a timed Petri net framework.

In a different work, an empty container repositioning policy with flexible destination ports was proposed by Song and Dong [16]. Proposed policy formulated mathematically and evaluated its effectiveness via simulation. Feo et al. [17] proposed a model to select the most appropriate freight transport mode between door-to-door road transport and the south-west Europe Motorway of the Sea. They estimate the subjective values of transport attributes by means of a binary discrete choice model as a support tool for designing an optimum promotion strategy for short sea shipping. Meng and Wang [18] proposed a novel intermodal hub-and-spoke network design problem for multitype container flows in the context of intermodal freight transportation operations. They developed a mathematical program with equilibrium constraints model for the proposed problem with multiple stakeholders. A hybrid genetic algorithm was proposed to solve the model by the authors.

In this study, while considering quantitative factors about the cost and time, qualitative and quantitative factors about transportation modes are also considered for the strategic planning process. Evaluating convenience degrees of transportation modes with a systematic and reliable methodology has an important effect on the determination of transshipment points and the local warehouses in the transportation network. In this study, analytic network process (ANP) approach is utilized to evaluate the transportation modes. Following the evaluation of the transportation modes phase, for each echelon of the multimodal transportation network, it is aimed to optimize the transportation between supply and demand. Transportation mode preference of the top management team, cost minimization aims of the operations department, and time minimization aims of the marketing department are tried to be satisfied with the multilevel programming (MLP) technique. There are three levels and eight objectives in the model and it is solved by fuzzy programming method which uses the concepts of tolerance membership function. Thanks to the max-min fuzzy operators, the problem is transformed to one level multiobjective model and then a satisfactory solution obtained for all levels. 
Some of the contributions of this study to the literature can be summarized as follows. (i) In the transportation modes evaluation phase, lots of criteria determined utilizing from related literature and interviews with experts from different hierarchical levels and departments are considered; (ii) different decision makers' objectives are taken into account with the hierarchy considerations; (iii) for the applications similar to the real transportation networks, it is possible to find solutions with the proposed methodology in a way that is not hard.

This study is organized as follows. In the next section mathematical background for the proposed approach are given. In the third section, the proposed solution approaches for the strategic planning of the multimodal transportation systems are explained. In the fourth section, a real world application is presented and the final section is the conclusions section.

\section{Strategic Planning Methodology for the Multimodal Transportation System}

2.1. Defining the Problem. Designing a transportation network is a strategic decision and it will affect many decision makers both from the inside and outside of the company. Therefore, choosing the right decision criteria, probable alternatives, and the people joining the decision process has vital importance. The logistics sector generally has a decentralized and hierarchical organization structure. For example, in a LSP, the upper level managers give some strategic decisions that can affect the transportation or warehouse operation managers who are in the lower management level. Besides, in the lower level management, the different geographic regions' or different departments' managers can also have different ideas. As a result, decisions given together with the upper and lower level managers may provide a coordination in LSPs. For example, while making long-term strategic decisions, like as constructing transshipment points and distribution centers to the convenient places, the top level management of the LSP should consider various conflicting criteria, that is, customer demands, product characteristics, safety requirements, reliability, and so forth. In the lower level, logistics operations department would probably focus on the operation costs, that is, transportation, transshipment, warehousing, and facility operating and investment cost. Since the lower level managers of these functional areas can have conflicting objectives, the upper and lower managers should give the strategic decision together. Due to the above mentioned reasons the problem transforms to a multilevel structure. Steps of the proposed methodology for modeling this problem and the used methods for solving the certain parts of the problem are summarized in Figure 1.

The general model representation of investigated transportation network and solution process have some assumptions. Considered transportation network is constituted from $\mathrm{N}$ echelons. There is no transportation between the inner points of each echelon and only the forward directed transportations are allowed. Transportations may be realized from any echelon to any further echelon and there is no necessity to visit all the echelons. Also, various combinations of the transportation modes may be utilized for the transportations.

In this study, a multicommodity, multiechelon, multimodal, multilevel, and multiobjective model are proposed. It is assumed that each product type has a standard shape and weight. Additionally, container and trailer transportation is possible with the consolidation of the products as unit freights. The general representation of the transportation network is customized to be constituted from four echelons as shown in Figure 2. First echelon of the network comprises the transportation from suppliers of exporter country to first transshipment terminals. Second echelon comprises the transportation between two transshipment terminals. These transshipment terminals are located in the exporter and importer countries, respectively. Third echelon comprises the part between arrival point and local warehouses of importer country. The last echelon comprises the part between local warehouses and the demand points.

In this study, the number of echelons is determined considering the transportation examples, which are generally constituted from four or less echelons between Turkey and Europe.

Due to the fact that airway transportation is not convenient for many freight types, it is not considered as an alternative transportation mode in this study. Transportation alternatives that are obtained with various combinations of transportation modes (see Figure 5) are as follows: (a) Road, (b) Road-Railway, (c) Road-Sea, and (d) Road-Sea-Railway.

For the multilevel transportation network design problem, there are more than one objective of the different levels tried to be optimized. Hierarchical structure of the multiple objectives can be seen in Figure 3 .

Considering the investigated problem, hierarchy structure could be established in a different manner or the number of the objectives might be changed. The reason of placing the total efficiency of transportation mode usage maximization at level 0 is to consider many criteria in weighting process. Evaluating the transportation modes according to a large number of comprehensive quantitative and qualitative criteria moves this objective to the highest level comparing with the other departmental objectives. Considering only cost and time based objectives will prevent to take into account inherent advantages of the transportation modes. In multimodal transportation especially, determining the transportation modes is relatively more important since transshipment terminals, like container ports or railroad terminals, will be chosen or constructed according to this decision. Thus, putting this objective to the top and sorting the other objectives as shown in Figure 3 will provide compromising solutions for the company. The reason of dividing level 1 objectives to level 2 objectives is to consider the separate opinions of decision makers who have conflicting objectives. For example, while the transportation operators deal with the cost and time of transportation activities, transshipment terminal operators focus on cost or time of the terminal operations. Upper level managers (level 1) have a holistic approach but lower level operators (level 2) take into account the tradeoffs among the activities. 


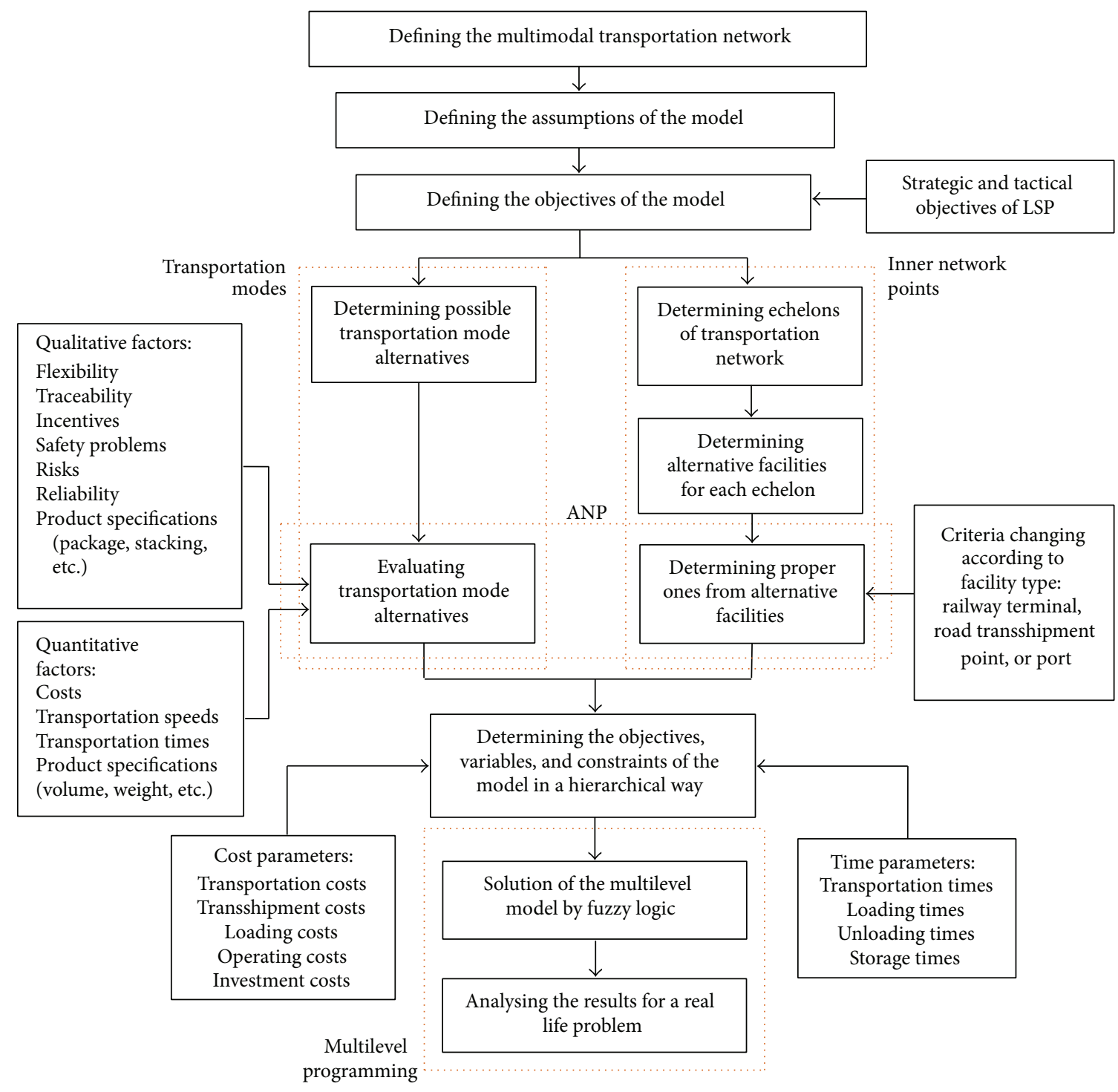

Figure 1: Proposed methodology.

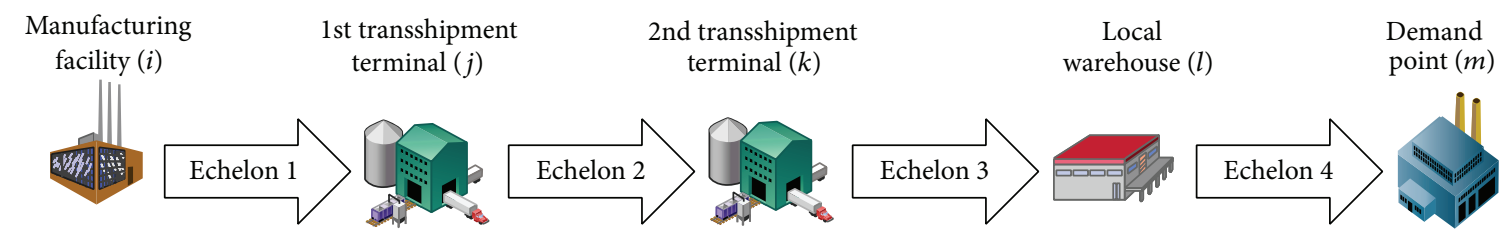

FIGURE 2: Transportation network design.

\subsection{Proposed Multimodal Transportation Network Design} Model. Indices, parameters, and decision variables of the model are explained as follows.

\section{Indices:}

$i$ : index for supply points;

$j$ : index for the first transshipment terminal;

$k$ : index for the second transshipment terminal;

$l$ : index for the local warehouses; $m$ : index for the demand points;

$p$ : index for the product types;

$a$ : index for the transportation modes.

\section{Parameters:}

$\lambda_{a}$ : weight of the transportation mode $a$;

$D_{p m}$ : demand volume of product $p$ from demand point $m$. 


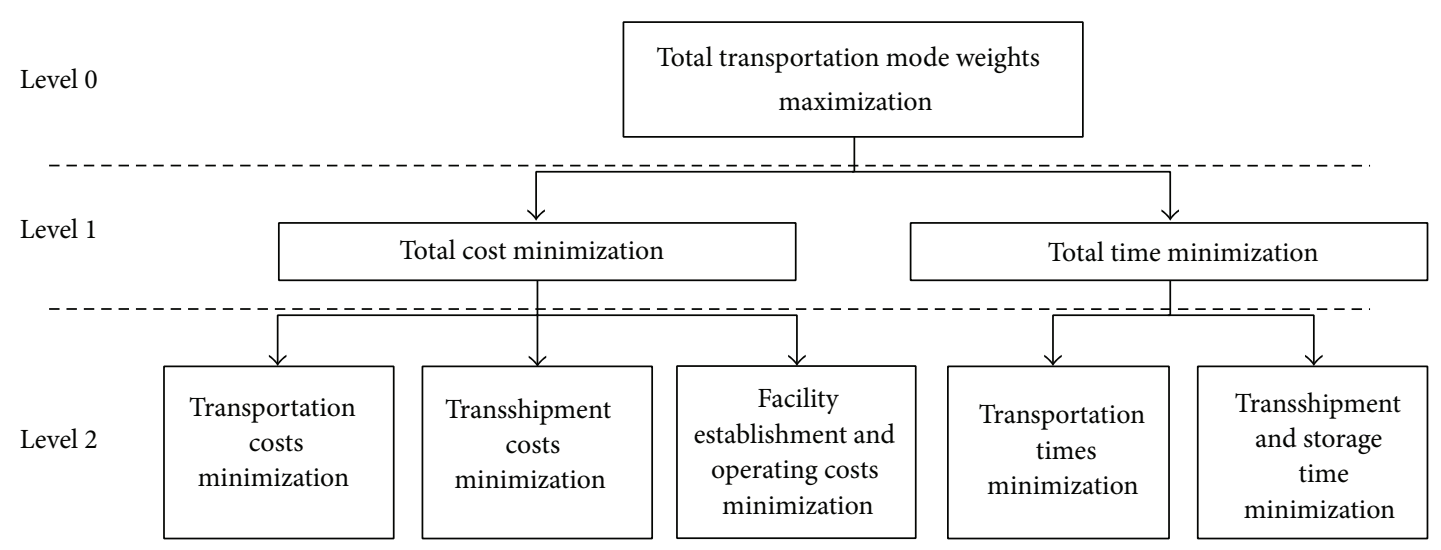

FIGURE 3: Hierarchy of the objectives.

Transportation cost of product $p$ between facilities and local warehouses $\left(\mathrm{CTr}_{\text {pila }}^{1}\right)$, facilities and 1st transshipment terminals $\left(\mathrm{CTr}_{p i j a}^{2}\right)$, 1st transshipment terminals and 2nd transshipment terminals $\left(\mathrm{CTr}_{p j k a}^{3}\right)$, 2nd transshipment terminals and demand points $\left(\mathrm{CTr}_{p k m a}^{4}\right)$, 2nd transshipment terminals and local warehouses $\left(\mathrm{CTr}_{p k l a}^{5}\right)$, and local warehouses and demand points $\left(\mathrm{CTr}_{\text {plma }}^{6}\right)$ with transportation mode $a$ (TL/unit product) are the first parameter group.

Transportation time of product $p$ between facilities and local warehouses $\left(\mathrm{TTr}_{\text {pila }}^{1}\right)$, facilities and 1st transshipment terminals $\left(\operatorname{TTr}_{p i j a}^{2}\right)$, 1st transshipment terminals and 2nd transshipment terminals $\left(\mathrm{TTr}_{p j k a}^{3}\right)$, 2nd transshipment terminals and demand points $\left(\operatorname{TTr}_{p k m a}^{4}\right)$, 2nd transshipment terminals and local warehouses $\left(\operatorname{TTr}_{p k l a}^{5}\right)$, local warehouses and demand points $\left(\mathrm{TTr}_{\text {plma }}^{6}\right.$ ) with transportation mode $a$ (hours/unit product) are the second parameter group.

CTrns $\underset{p * a}{* \text {,unload }}$ is the unloading cost of product $p$ (with pallet) transported via transportation mode $a$ in transshipment terminals or local warehouses (TL/unit product).

$\mathrm{CTrns}_{p * a}^{* \text {,unload }}$ is loading cost of product $p$ (with pallet) which is to be transported via transportation mode $a$ in transshipment terminals or local warehouses (TL/unit product).

TTrns $\underset{p * a}{* \text {,unload }}$ is the unloading time of product $p$ (with pallet) transported via transportation mode $a$ in transshipment terminals or local warehouses (hours/unit product).

TTrns $\underset{p * a}{* \text { unload }}$ is loading time of product $p$ (with pallet) which is to be transported via transportation mode $a$ in transshipment terminals or local warehouses (hours/unit product).

CWhs $_{p * a}^{*}$ is waiting cost of product $p$ (transported via transportation mode $a$ ) in the storage area of the transshipment terminals and local warehouses (TL/unit product).

$\mathrm{TWhs}_{p * a}^{*}$ is waiting time of product $p$ (transported via transportation mode $a$ ) in the storage area of the transshipment terminals and local warehouses (hours/unit product).
Cap $_{*}$ is capacities of transshipment terminals and local warehouses for one planning period (container/one planning period).

$\mathrm{CEst}_{*}^{*}$ is establishment cost of transshipment terminals and local warehouses (TL).

$\mathrm{COpr}_{*}^{*}$ is operating cost of transshipment terminals and local warehouses (TL).

2.2.1. Decision Variables. The decision variables are the transported volumes of product $p$ between facilities and local warehouses $\left(X_{\text {pila }}^{1}\right)$, facilities and 1st transshipment points $\left(X_{p i j a}^{2}\right)$, 1st transshipment points and 2nd transshipment points $\left(X_{p j k a}^{3}\right)$, 2nd transshipment points and demand points $\left(X_{p k m a}^{4}\right), 2$ nd transshipment points and local warehouses $\left(X_{p k l a}^{5}\right)$, and local warehouses and demand points $\left(X_{p l m a}^{6}\right)$ with transportation mode $a$.

$Y_{j}^{J}$ : Establishment decision on transshipment terminal $j, Y_{j}^{J} \in\{0,1\}$,

$Y_{k}^{K}$ : Establishment decision on transshipment terminal $k, Y_{k}^{K} \in\{0,1\}$,

$Y_{k}^{K}$ : Establishment decision on local warehouse $l$, $Y_{l}^{L} \in\{0,1\}$.

Given the above nomenclature, proposed multimodal transportation model is presented as follows.

2.2.2. Objective Functions. The first objective function is the maximization of the weighted transportation volume of the modes (1). The weights are obtained by the evaluations 
of the transportation modes using ANP and explained in Section 3.1. Consider

$$
\begin{aligned}
\max z_{1}=\sum_{a=1}^{A} \lambda_{a}\left(\sum_{p=1}^{P} \sum_{i=1}^{I} \sum_{l=1}^{L} X_{p i l a}^{1}\right. \\
+\sum_{p=1}^{P} \sum_{i=1}^{I} \sum_{j=1}^{J} X_{p i j a}^{2} \\
+\sum_{p=1}^{P} \sum_{j=1}^{J} \sum_{k=1}^{K} X_{p j k a}^{3} \\
+\sum_{p=1}^{P} \sum_{k=1}^{K} \sum_{m=1}^{M} X_{p k m a}^{4} \\
+\sum_{p=1}^{P} \sum_{k=1}^{K} \sum_{l=1}^{L} X_{p k l a}^{5} \\
\left.+\sum_{p=1}^{P} \sum_{l=1}^{L} \sum_{m=1}^{M} X_{p l m a}^{6}\right) ;
\end{aligned}
$$

second objective function is the total cost minimization and it is concerning the operations of the transportation department. Transportation department's management is responsible to the top management about the minimization of the department's operational costs. The transportation cost, facilities' establishment and operating cost, and the cost occurred at the transshipment terminals and local warehouses are the elements of this objective function:

$$
\begin{aligned}
\min z_{2}= & \sum_{p=1}^{P} \sum_{i=1}^{I} \sum_{l=1}^{L} \sum_{a=1}^{A} \mathrm{CTr}_{p i l a}^{1} X_{p i l a}^{1} \\
& +\sum_{p=1}^{P} \sum_{i=1}^{I} \sum_{j=1}^{J} \sum_{a=1}^{A} \mathrm{CTr}_{p i j a}^{2} X_{p i j a}^{2} \\
& +\sum_{p=1}^{P} \sum_{j=1}^{J} \sum_{k=1}^{K} \sum_{a=1}^{A} \mathrm{CTr}_{p i k a}^{3} X_{p j k a}^{3} \\
& +\sum_{p=1}^{P} \sum_{k=1}^{K} \sum_{m=1}^{M} \sum_{a=1}^{A} \mathrm{CTr}_{p k m a}^{4} X_{p k m a}^{4} \\
& +\sum_{p=1}^{P} \sum_{k=1}^{K} \sum_{l=1}^{L} \sum_{a=1}^{A} \mathrm{CTr}_{p k l a}^{5} X_{p k l a}^{5} \\
& +\sum_{p=1}^{P} \sum_{l=1}^{L} \sum_{m=1}^{M} \sum_{a=1}^{A} \mathrm{CTr}_{p l m a}^{6} X_{p l m a}^{6}
\end{aligned}
$$

$$
\begin{aligned}
& +\sum_{p=1}^{P} \sum_{i=1}^{I} \sum_{j=1}^{J} \sum_{a=1}^{A}\left(\mathrm{CTrns}_{p j a}^{J, \text { unload }}+\mathrm{CWhs}_{p j a}^{J}\right) X_{p i j a}^{2} \\
& +\sum_{p=1}^{P} \sum_{j=1}^{J} \sum_{k=1}^{K} \sum_{a=1}^{A} \mathrm{CTrns}_{p j a}^{J, \mathrm{load}} X_{p j k a}^{3} \\
& +\sum_{p=1}^{P} \sum_{j=1}^{J} \sum_{k=1}^{K} \sum_{a=1}^{A}\left(\mathrm{CTrns}_{p k a}^{K, \text { unload }}+\mathrm{CWhs}_{p k a}^{K}\right) X_{p j k a}^{3} \\
& +\sum_{p=1}^{P} \sum_{k=1}^{K} \sum_{l=1}^{L} \sum_{a=1}^{A} \mathrm{CTrns}_{p k a}^{K, \text { load }} X_{p k l a}^{5} \\
& +\sum_{p=1}^{P} \sum_{k=1}^{K} \sum_{l=1}^{L} \sum_{a=1}^{A}\left(\mathrm{CTrns}_{p l a}^{L, \text { unload }}+\mathrm{CWhs}_{p l a}^{L}\right) X_{p k l a}^{5} \\
& +\sum_{p=1}^{P} \sum_{l=1}^{L} \sum_{m=1}^{M} \sum_{a=1}^{A} \mathrm{CTrns}_{\text {pla }}^{L, \text { load }} X_{\text {plma }}^{6} \\
& +\sum_{p=1}^{P} \sum_{i=1}^{I} \sum_{l=1}^{L} \sum_{a=1}^{A}\left(\mathrm{CTrns}_{\text {pla }}^{L, \text { unload }}+\mathrm{CWhs}_{\text {pla }}^{L}\right) X_{\text {pila }}^{1} \\
& +\sum_{p=1}^{P} \sum_{k=1}^{K} \sum_{m=1}^{M} \sum_{a=1}^{A} \mathrm{CTrns}_{p k a}^{K, \text { load }} X_{p k m a}^{4} \\
& +\sum_{j=1}^{J} Y_{j}^{J}\left(\mathrm{CEst}_{j}^{J}+\mathrm{COpr}_{j}^{J}\right) \\
& +\sum_{k=1}^{K} Y_{k}^{K}\left(\mathrm{CEst}_{k}^{K}+\mathrm{COpr}_{k}^{K}\right) \\
& +\sum_{l=1}^{L} Y_{l}^{L}\left(\mathrm{CEst}_{l}^{L}+\mathrm{COpr}_{l}^{L}\right)
\end{aligned}
$$

third objective function $\left(z_{3}\right)$ is total transportation costs minimization. It is occurred during the transportation and calculated as the multiplication of the transported product volume and unit transportation cost. This cost will be changed according to combination of the transportation modes and can be formulated as the summation of first and second lines of (2).

Fourth objective function $\left(z_{4}\right)$ is total transshipment costs. During the transportation mode changes in the transshipment terminals and local warehouses, this cost occurs with the unloading, storing, and loading activities and calculated as the multiplication of the unit unloading, storing, and loading costs by product volume. This cost will be changed according to the transportation modes utilizing for coming to or leaving from the transshipment terminals and local warehouses. It can be formulated as the summation of third, fourth, fifth, and sixth lines of (2). 
Fifth objective function $\left(z_{5}\right)$ is the facility establishment and operating costs minimization and these costs occur during establishment and operating of local warehouses and transshipment terminals in the first and second echelon. These costs constitute two parts, initial investment costs and yearly operating costs, and will be changed according to the location of the facility. It can be formulated as the last line of (2). In this stage, it is assumed that operating costs of facilities are not affected by the product.

Sixth objective function is the total time minimization. Last three objectives are related to the marketing department of the LSP. Management of marketing department is responsible for the top management to satisfy customers via decreasing the transportation times for faster deliveries. The components of the total time are transportation times between the echelons, unloading times in the transshipment terminals, and local warehouses, waiting in the storage areas of the facilities and loading to the vehicles (3). Consider

$$
\begin{aligned}
& \min z_{6}=\sum_{p=1}^{P} \sum_{i=1}^{I} \sum_{l=1}^{L} \sum_{a=1}^{A} \operatorname{TTr}_{\text {pila }}^{1} X_{\text {pila }}^{1} \\
& +\sum_{p=1}^{P} \sum_{i=1}^{I} \sum_{j=1}^{J} \sum_{a=1}^{A} \mathrm{TTr}_{p i j a}^{2} X_{p i j a}^{2} \\
& +\sum_{p=1}^{P} \sum_{j=1}^{J} \sum_{k=1}^{K} \sum_{a=1}^{A} \operatorname{TTr}_{p j k a}^{3} X_{p j k a}^{3} \\
& +\sum_{p=1}^{P} \sum_{k=1}^{K} \sum_{m=1}^{M} \sum_{a=1}^{A} \mathrm{TTr}_{p k m a}^{4} X_{p k m a}^{4} \\
& +\sum_{p=1}^{P} \sum_{k=1}^{K} \sum_{l=1}^{L} \sum_{a=1}^{A} \mathrm{TTr}_{p k l a}^{5} X_{p k l a}^{5} \\
& +\sum_{p=1}^{P} \sum_{l=1}^{L} \sum_{m=1}^{M} \sum_{a=1}^{A} \operatorname{TTr}_{p l m a}^{6} X_{p l m a}^{6} \\
& +\sum_{p=1}^{P} \sum_{i=1}^{I} \sum_{j=1}^{J} \sum_{a=1}^{A}\left(\mathrm{TTrns}_{p j a}^{J, \text { unload }}+\mathrm{TWhs}_{p j a}^{J}\right) X_{p i j a}^{2} \\
& +\sum_{p=1}^{P} \sum_{j=1}^{J} \sum_{k=1}^{K} \sum_{a=1}^{A} \operatorname{TTrns}_{p j a}^{J, \text { load }} X_{p j k a}^{3} \\
& +\sum_{p=1}^{P} \sum_{j=1}^{J} \sum_{k=1}^{K} \sum_{a=1}^{A}\left(\operatorname{TTrns}_{p k a}^{K, \text { unload }}+\text { TWhs }_{p k a}^{K}\right) X_{p j k a}^{3} \\
& +\sum_{p=1}^{P} \sum_{k=1}^{K} \sum_{l=1}^{L} \sum_{a=1}^{A} \operatorname{TTrns}_{p k a}^{K, \text { load }} X_{p k l a}^{5} \\
& +\sum_{p=1}^{P} \sum_{k=1}^{K} \sum_{l=1}^{L} \sum_{a=1}^{A}\left(\mathrm{TTns}_{p l a}^{L, \text { unload }}+\mathrm{TWhs}_{p l a}^{L}\right) X_{p k l a}^{5}
\end{aligned}
$$

$$
\begin{aligned}
& +\sum_{p=1}^{P} \sum_{l=1}^{L} \sum_{m=1}^{M} \sum_{a=1}^{A} \operatorname{TTrns}_{p l a}^{L, \text { load }} X_{p l m a}^{6} \\
& +\sum_{p=1}^{P} \sum_{k=1}^{K} \sum_{l=1}^{L} \sum_{a=1}^{A}\left(\mathrm{TTrns}_{p l a}^{L, \text { unload }}+\mathrm{TWhs}_{\text {pla }}^{L}\right) X_{p i l a}^{1} \\
& +\sum_{p=1}^{P} \sum_{k=1}^{K} \sum_{m=1}^{M} \sum_{a=1}^{A} \operatorname{TTrns}_{p k a}^{K, \text { load }} X_{p k m a}^{4} .
\end{aligned}
$$

Transportation times are generally changeable; however, in this study it is assumed that they are deterministic. Decision makers' opinions and the statistical data are taken into account for determining the transportation times.

Seventh objective function $\left(z_{7}\right)$ is total transportation time minimization and it is related to the multiplication of the transportation time changing according to the chosen transportation mode and product volume transported with this mode. It can be formulated as the summation of the first two lines of (3).

Eighth objective function $\left(z_{8}\right)$ is total transshipment and storage time minimization and this time is calculated with the multiplication of the product volume and unit transshipment and storage times occurred with the loading/unloading activities and waiting in the storage areas of the transshipment terminals and local warehouses. Transshipment and storage times will be changed according to the transportation modes used for coming to or leaving from the transshipment terminals and local warehouses. It can be formulated as the summation of last four lines of (3).

2.2.3. Constraints of the Model. Equation (4) tries to ensure that total demand of each demand point for each product type is satisfied. Demand for a certain product type from demand points may be satisfied from different manufacturing facilities:

$$
\sum_{k=1}^{K} \sum_{a=1}^{A} X_{p k m a}^{4}+\sum_{l=1}^{L} \sum_{a=1}^{A} X_{p l m a}^{6}=D_{p m}, \quad \forall p \in P, m \in M .
$$

Equation (5) tries to ensure that coming product volume to a transshipment terminal is equal to leaving product volume from this transshipment terminal:

$$
\sum_{i=1}^{I} \sum_{j=1}^{J} \sum_{a=1}^{A} X_{p i j a}^{2}=\sum_{j=1}^{J} \sum_{k=1}^{K} \sum_{a=1}^{A} X_{p j k a}^{3}, \quad \forall p \in P, \forall j \in J .
$$

In this representation, it is assumed that all types of products may be obtained from each facility. However, if it is needed in the application phase, a constraint on demand for satisfying certain types of products from certain facilities may be added.

Equation (6) tries to ensure that coming product volume to the second transshipment terminals from the first transshipment terminals is equal to leaving product volume of 


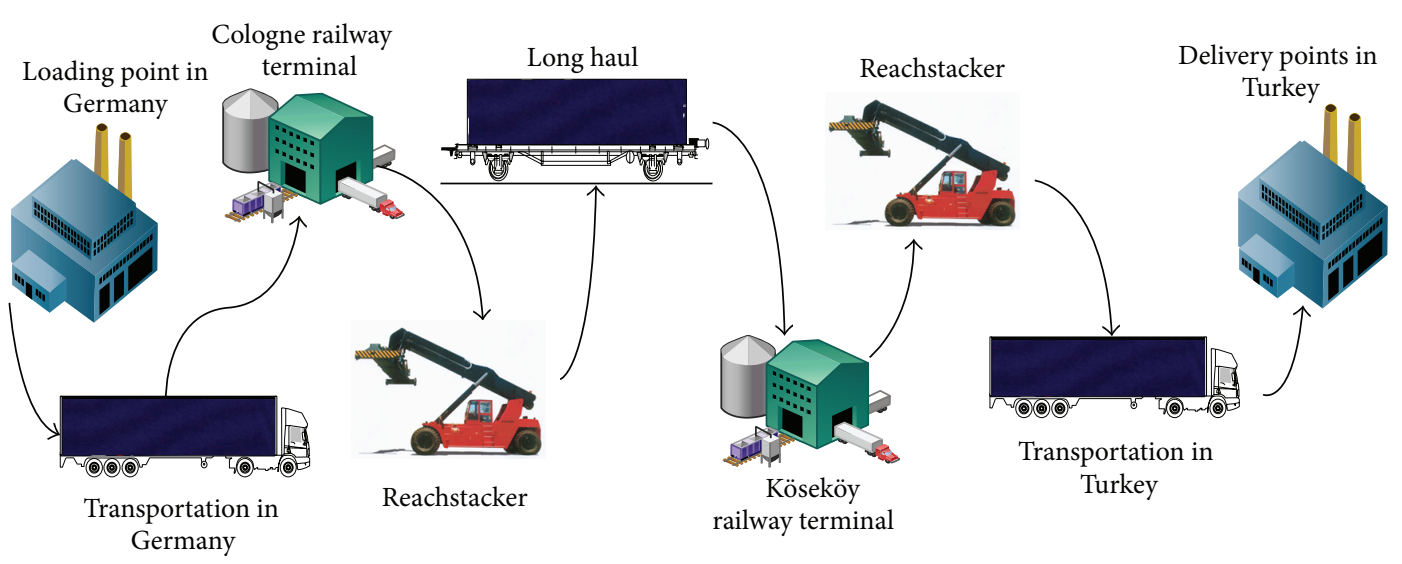

FIGURE 4: Flow in the current multimodal transportation.

the second transshipment terminals to local warehouses and demand points:

$$
\begin{array}{r}
\sum_{j=1}^{J} \sum_{k=1}^{K} \sum_{a=1}^{A} X_{p j k a}^{3}=\sum_{k=1}^{K} \sum_{l=1}^{L} \sum_{a=1}^{A} X_{p k l a}^{5}+\sum_{k=1}^{K} \sum_{m=1}^{M} \sum_{a=1}^{A} X_{p k m a}^{4} \\
\forall p \in P, \quad \forall k \in K .
\end{array}
$$

Equation (7) tries to ensure that coming product volume to local warehouses from supplier facilities and the second transshipment terminals is equal to leaving product volume from local warehouses to demand points:

$$
\begin{array}{r}
\sum_{i=1}^{I} \sum_{l=1}^{L} \sum_{a=1}^{A} X_{p i l a}^{1}+\sum_{k=1}^{K} \sum_{l=1}^{L} \sum_{a=1}^{A} X_{p k l a}^{5} \\
=\sum_{l=1}^{L} \sum_{m=1}^{M} \sum_{a=1}^{A} X_{p l m a}^{6} \\
\forall p \in P, \quad \forall l \in L .
\end{array}
$$

This constraint also necessitates that products transferred from facilities cannot be sent to demand points directly and, therefore, local warehouses should be used. In the real life cases, direct transportations from manufacturing facilities to demand points can be realized. However, in this study it is assumed that even small sized demands are ordered from demand points; they can only be satisfied from local warehouses.

Equations (8) are related with the capacities of all the points in each echelon of the network. Additionally, the products waiting in the transshipment terminals and local warehouses are assumed to be containerized freight and the capacities are given as container units not product units:

$$
\begin{gathered}
\sum_{p=1}^{P} \sum_{i=1}^{I} \sum_{a=1}^{A} X_{p i j a}^{2} \leq \operatorname{Cap}_{j} Y_{j}^{J}, \quad \forall j \in J, \\
\sum_{p=1}^{P} \sum_{j=1}^{J} \sum_{a=1}^{A} X_{p j k a}^{3} \leq \operatorname{Cap}_{k} Y_{k}^{K}, \quad \forall k \in K, \\
\sum_{p=1}^{P} \sum_{k=1}^{K} \sum_{a=1}^{A} X_{p k l a}^{5}+\sum_{p=1}^{P} \sum_{i=1}^{I} \sum_{a=1}^{A} X_{p i l a}^{1} \leq \operatorname{Cap}_{l} Y_{l}^{L}, \quad \forall l \in L .
\end{gathered}
$$

Capacity constraints in the model are only related to the capacities of the transshipment terminals and local warehouses. However, when considering the containers' reverse operations and especially the density degree for the railway transportation, a capacity constraint may be added for each transportation mode.

Since only certain transportation modes are available for the each transshipment terminal in our application, transshipment terminals' capacity constraints also restrict the transportation modes' utilization in one respect.

\section{Solution Approaches}

As mentioned previously, two solution approaches are combined to solve the proposed model. Firstly ANP provides the priority values of the alternative transportation modes and locations that are used as input values for the multilevel programming technique in the second stage of the model. Details of the solution approaches are given below.

3.1. Analytic Network Process. The ANP is a comprehensive framework available for the analysis of alternative actions in various areas [19-22]. It allows both interaction and feedback within clusters of elements (inner dependence) and between clusters (outer dependence). The feedback element captures the complex effects of interplay in human society, especially when risk and uncertainty are involved. The elements in a cluster may influence other elements that are in the same cluster or in other clusters with respect to several properties. The main objective in the process is to determine the overall influence of all the elements in conjunction with each other. For the detailed information and different application area examples see Saaty [23], Saaty and Vargas [24], and Saaty $[25]$

3.2. Multilevel Programming. Multilevel optimization models are used for solution of the problems which contains hierarchical structures [26-29]. In recent years especially, it is proved that multilevel programming (MLP) can be applied to different areas successfully, thanks to the increased interest of the academicians to this subject and finding new solution methods which can solve larger problems [30-32]. 
TABLE 1: Product based transportation costs $\left(\mathrm{CTr}_{\text {pila }}^{1}\right)$ from manufacturing facilities in Germany to local warehouses in Turkey (TL/product unit).

\begin{tabular}{|c|c|c|c|c|c|c|c|c|c|c|c|c|}
\hline \multirow{2}{*}{ Prd. } & \multicolumn{3}{|c|}{ Berlin } & \multicolumn{3}{|c|}{ Munich } & \multicolumn{3}{|c|}{ Hannover } & \multicolumn{3}{|c|}{ Cologne } \\
\hline & Ç. köy & Eskişehir & İzmit & Ç. köy & Eskişehir & İzmit & Ç. köy & Eskişehir & İzmit & Ç. köy & Eskişehir & İzmit \\
\hline 1 & 493.3 & 559.1 & 513.3 & 425.4 & 492.2 & 446.1 & 554.5 & 621.0 & 575.2 & 554.3 & 620.8 & 574.7 \\
\hline 2 & 1183.9 & 1341.9 & 1231.9 & 1021.0 & 1181.2 & 1070.7 & 1330.7 & 1490.4 & 1380.4 & 1330.2 & 1489.9 & 1379.3 \\
\hline 3 & 394.6 & 447.3 & 410.7 & 340.3 & 393.7 & 356.9 & 443.6 & 496.8 & 460.1 & 443.4 & 496.6 & 459.8 \\
\hline 4 & 328.9 & 372.8 & 342.2 & 283.6 & 328.1 & 297.4 & 369.7 & 414.0 & 383.4 & 369.5 & 413.9 & 383.2 \\
\hline 5 & 739.9 & 838.7 & 770.0 & 638.1 & 738.3 & 669.2 & 831.7 & 931.5 & 862.7 & 831.4 & 931.2 & 862.1 \\
\hline
\end{tabular}

TABLE 2: Product based transportation times $\left(\operatorname{TTr}_{\text {pila }}^{1}\right)$ from manufacturing facilities in Germany to local warehouses in Turkey (hour/container).

\begin{tabular}{lccc}
\hline & Çerkezköy & Eskişehir & İzmit \\
\hline Berlin & 47.5 & 50.5 & 48 \\
Hannover & 48.5 & 51.5 & 49 \\
Munich & 43 & 46.5 & 44 \\
Cologne & 48 & 51 & 49 \\
\hline
\end{tabular}

There are various methods used for the solution of MLP in the literature. First category is extreme point search and the included methods in this category search a compromise vertex for decision variables by using simplex algorithm [29]. In transformation approach category, the lower level problems are tried to be made the constraints of the upper level problems. It can be realized by using Karush-KhunTucker optimality conditions or penalty function techniques [33]. Nonlinear or discrete MLP can also be solved by gradient or branch and bound techniques [34]. Heuristics, comparatively new methods, are another category for solving MLP. Generally evolutionary algorithms [35] are used in the literature. As the last category, fuzzy approach is especially convenient for the large sized MLP problems and can deal with the calculation complexity successfully. Shih et al. [36] proposed a fuzzy approach for a bilevel programming model by defining fuzzy objective functions for each level and fuzzy decision variables for upper level. Then Sakawa et al. [37] improved the same problem and Shih and Lee [38] used compensatory operators for the multiobjectives of each level.

Because of the above mentioned advantages, fuzzy programming approach is used for the solution of the multilevel problem in this study. As the solution procedure, first, the problem is solved for each objective of the each level separately as given in (9) (it should be considered that the objective function can also be minimization). $i$ is the index of the objective function level and $j$ is the index of decision maker for each level; $\bar{x}_{i j}$ is the decision vector of the objective function $j$ in level $i$ and $G$ is the hard constraint set inherent to the problem. Consider

$$
\begin{array}{ll}
\operatorname{Max}_{\bar{x}_{i j}} & f_{i j}(\bar{x}), \quad i=1,2, \ldots, b, j=1,2, \ldots, N_{j}, \\
\text { s.t. } & \bar{x}_{i j} \in G, \\
& \bar{x}=\left(x_{1}, x_{2}, \ldots, x_{b}\right), \quad \bar{x} \in R^{n_{1}+n_{2}+\cdots+n_{b}} .
\end{array}
$$

After solving the problem for each objective function in each level, the optimal results denoted with $f_{i j}^{U}$ are obtained. Then the worst results are calculated for each objective function by replacing the objective functions' optimal results with each other $\left(f_{i j}^{L}\right)$. The gap between $f_{i j}^{U}$ and $f_{j i}^{L}$ values shows the tolerances of each objective function. While all objectives are considered together, a compromise solution will be reached. To satisfy all levels' objectives together, a compensatory operator is also used. Furthermore, if the decision variables of the objectives are different, tolerance values $\left(\bar{e}_{i j}\right)$ can be used for them. The general model structure is shown in the following:

$$
\begin{aligned}
& \max \lambda \\
& \text { s.t. } \quad \frac{\left[\bar{x}_{i j}-\left(\bar{x}_{i j}^{*}-\bar{e}_{i j}^{-}\right)\right]}{\bar{e}_{i j}^{-}} \geq \lambda I, \quad i=1,2, \ldots, b-1 ; \\
& j=1,2, \ldots, N_{j}, \\
& \frac{\left[\left(\bar{x}_{i j}^{*}+\bar{e}_{i j}^{+}\right)-\bar{x}_{i j}\right]}{\bar{e}_{i j}^{+}} \geq \lambda I, \quad i=1,2, \ldots, b-1 ; \\
& j=1,2, \ldots, N_{j}, \\
& \frac{\left[f_{i j}(\bar{x})-f_{i j}^{L}\right]}{\left[f_{i j}^{U}-f_{i j}^{L}\right]} \geq \lambda, \quad i=1,2, \ldots, b ; \\
& j=1,2, \ldots, N_{j}, \\
& g_{r}\left(\bar{x}_{i j}\right) \leq 0, \quad i=1,2, \ldots, b ; j=1,2, \ldots, N_{j}, \\
& \bar{x}_{i j} \in G, \quad i=1,2, \ldots, b ; j=1,2, \ldots, N_{j} .
\end{aligned}
$$

Here the objective function tries to maximize the satisfaction degree $(\lambda)$ of the worst objective and decision variable values considering the tolerance gaps of them. First two constraint sets restrict the decision variable values from negative and positive sides. The third constraint set is related with the satisfaction degree of the objective functions. The remaining are the hard constraints inherent to the problem. For detailed information see Shi and Xia [39] and Osman et al. [40]. 
TABLE 3: Transportation costs from the manufacturing facilities to the first level from transshipment terminals (TL/unit product).

\begin{tabular}{|c|c|c|c|c|c|c|c|c|c|c|c|}
\hline Product & $t$ Mode & & Berlin & Munich & Hannover & Cologne & & Berlin & Munich & Hannover & Cologne \\
\hline \multirow{2}{*}{1} & Railway & \multirow{10}{*}{ Cologne Railway Terminal } & 92.52 & 93.82 & 48.13 & 4.90 & \multirow{10}{*}{ Hamburg Port } & 51.07 & 125.48 & 29.21 & 68.86 \\
\hline & Road & & 127.27 & 129.05 & 64.75 & 4.45 & & 64.08 & 175.33 & 33.60 & 94.12 \\
\hline \multirow{2}{*}{2} & Railway & & 222.04 & 225.17 & 115.52 & 11.75 & & 122.57 & 301.14 & 70.10 & 165.26 \\
\hline & Road & & 305.45 & 309.72 & 155.39 & 10.68 & & 153.79 & 420.79 & 80.63 & 225.88 \\
\hline \multirow{2}{*}{3} & Railway & & 74.01 & 75.06 & 38.51 & 3.92 & & 40.86 & 100.38 & 23.37 & 55.09 \\
\hline & Road & & 101.82 & 103.24 & 51.80 & 3.56 & & 51.26 & 140.26 & 26.88 & 75.29 \\
\hline \multirow{2}{*}{4} & Railway & & 61.68 & 62.55 & 32.09 & 3.26 & & 34.05 & 83.65 & 19.47 & 45.90 \\
\hline & Road & & 84.85 & 86.03 & 43.17 & 2.97 & & 42.72 & 116.89 & 22.40 & 62.75 \\
\hline \multirow{2}{*}{5} & Railway & & 138.77 & 140.73 & 72.20 & 7.34 & & 76.61 & 188.21 & 43.81 & 103.28 \\
\hline & Road & & 190.91 & 193.58 & 97.12 & 6.68 & & 96.12 & 263.00 & 50.40 & 141.18 \\
\hline \multirow{2}{*}{1} & Railway & \multirow{10}{*}{ Passau Railway Terminal } & 104.43 & 30.68 & 106.55 & 108.18 & \multirow{10}{*}{ Trieste Port } & 176.71 & 86.32 & 178.34 & 180.14 \\
\hline & Road & & 136.84 & 43.17 & 153.75 & 137.95 & & 242.75 & 114.14 & 253.87 & 241.19 \\
\hline \multirow{2}{*}{2} & Railway & & 250.62 & 73.62 & 255.71 & 259.63 & & 424.10 & 207.16 & 428.02 & 432.33 \\
\hline & Road & & 328.41 & 103.60 & 368.99 & 331.08 & & 582.59 & 273.94 & 609.29 & 578.86 \\
\hline \multirow{2}{*}{3} & Railway & & 83.54 & 24.54 & 85.24 & 86.54 & & 141.37 & 69.05 & 142.67 & 144.11 \\
\hline & Road & & 109.47 & 34.53 & 123.00 & 110.36 & & 194.20 & 91.31 & 203.10 & 192.95 \\
\hline \multirow{2}{*}{4} & Railway & & 69.62 & 20.45 & 71.03 & 72.12 & & 117.81 & 57.54 & 118.89 & 120.09 \\
\hline & Road & & 91.23 & 28.78 & 102.50 & 91.97 & & 161.83 & 76.10 & 169.25 & 160.79 \\
\hline \multirow{2}{*}{5} & Railway & & 156.64 & 46.01 & 159.82 & 162.27 & & 265.06 & 129.47 & 267.51 & 270.20 \\
\hline & Road & & 205.26 & 64.75 & 230.62 & 206.93 & & 364.12 & 171.21 & 380.81 & 361.79 \\
\hline
\end{tabular}

TABLE 4: Transportation times between the manufacturing facilities and the first level transshipment terminals (hour/container).

\begin{tabular}{lcccccccc}
\hline & \multicolumn{2}{c}{ Cologne Railway Terminal } & \multicolumn{2}{c}{ Passau Railway Terminal } & \multicolumn{2}{c}{ Hamburg Port } & \multicolumn{2}{c}{ Trieste Port } \\
& Railway & Road & Railway & Road & Railway & Road & Railway & Road \\
\hline Berlin & 12 & 7.5 & 18 & 8 & 10 & 4 & 23 \\
Munich & 18 & 7.5 & 4 & 2.5 & 20 & 10 & 16 \\
Hannover & 6 & 4 & 18 & 9 & 3 & 2 & 7 \\
Cologne & 1 & 0.5 & 16 & 8 & 6 & 5.5 & 23 \\
\hline
\end{tabular}

\section{An Application for the Case of Turkey}

Application is realized for a LSP from Turkey. A real life project of this firm which uses multimodal transportation network in international scale is investigated for this study. This LSP transports a large-scale manufacturer's products continuously and also a certain number of different firms that have less than truckload (LTL) freights are the contracted customers of it. In the current situation, freights are collected from initial producers in Germany and transported by road to a center in the railway terminal for consolidation. Then long haul transportation is realized via railway transportation mode to the arrival railway terminal in Turkey. After the arrival terminal, freights may directly dispatch to the customers or may send local warehouses by road transportation mode. Current multimodal transportation is depicted in Figure 4.

Manufacturing facilities of the exporter country are located in four different locations in Germany, namely, Berlin, Munich, Hannover, and Cologne. Collected freights from these locations are consolidated in Cologne Railway Terminal. Freights are transported by railway mode from Cologne to Köseköy in Turkey. From Köseköy, freights are transported to different demand points in the west of Turkey by road transportation mode. Rarely, whole transportation between Germany and Turkey are realized via road transportation mode during demand fluctuation periods.

Beside the currently used transportation routes, alternative ones are tried to be determined via proposed methodology. After explaining the general structure of the current transportation network, the details of the transportation modes evaluation by using the ANP are given. Then second application of the ANP for selecting the convenient ports which are the arriving points of long haul in Turkey is presented. The reason of applying port selection process for only this echelon is related with the strategic importance of this stage for the LSP which displays activity in importer country. Transshipment terminals in other echelons are determined considering the expert opinions. In the remaining part of the case study, the collected important numerical data are presented, the proposed multilevel programming model is applied, results are analyzed, and obtained results are compared with the current network. 
TABLE 5: Transportation costs from the first to the second transshipment terminals (TL/unit product).

\begin{tabular}{|c|c|c|c|c|c|c|c|c|c|c|c|c|c|}
\hline \multirow[t]{2}{*}{ Prd. } & \multirow{2}{*}{ Mode } & \multirow{2}{*}{$\begin{array}{c}\text { Cologne } \\
\text { Railway } \\
\text { Terminal } \\
\text { H.pasa }\end{array}$} & \multirow{2}{*}{$\begin{array}{c}\text { Passau } \\
\text { Railway } \\
\text { Terminal } \\
\text { H.pasa }\end{array}$} & \multicolumn{5}{|c|}{ Hamburg Port } & \multicolumn{5}{|c|}{ Trieste Port } \\
\hline & & & & Marport & Gemlik & Akport & LSP Port & H.pasa & Marport & Gemlik & Akport & LSP Port & H.pasa \\
\hline \multirow{2}{*}{1} & Railway & 370.8 & 326.3 & \multicolumn{5}{|c|}{ No transportation } & \multicolumn{5}{|c|}{ No transportation } \\
\hline & Sea & NT & NT & 356.2 & 367.2 & 341.2 & 341.2 & 356.2 & 279.0 & 285.0 & 267.0 & 267.0 & 279.0 \\
\hline \multirow{2}{*}{2} & Railway & 890.0 & 783.2 & \multicolumn{5}{|c|}{ No transportation } & \multicolumn{5}{|c|}{ No transportation } \\
\hline & Sea & NT & NT & 833.8 & 844.8 & 818.8 & 818.8 & 833.8 & 652.8 & 653.8 & 640.8 & 640.8 & 652.8 \\
\hline \multirow{2}{*}{3} & Railway & 296.7 & 261.1 & \multicolumn{5}{|c|}{ No transportation } & \multicolumn{5}{|c|}{ No transportation } \\
\hline & Sea & NT & NT & 287.9 & 298.9 & 272.9 & 272.9 & 287.9 & 225.6 & 226.6 & 213.6 & 213.6 & 225.6 \\
\hline \multirow{2}{*}{4} & Railway & 247.2 & 217.6 & \multicolumn{5}{|c|}{ No transportation } & \multicolumn{5}{|c|}{ No transportation } \\
\hline & Sea & NT & NT & 242.4 & 253.4 & 227.4 & 227.4 & 242.4 & 190.0 & 191.0 & 178.0 & 178.0 & 190.0 \\
\hline \multirow{2}{*}{5} & Railway & 556.3 & 489.5 & \multicolumn{5}{|c|}{ No transportation } & \multicolumn{5}{|c|}{ No transportation } \\
\hline & Sea & NT & NT & 526.8 & 537.8 & 511.8 & 511.8 & 526.8 & 412.5 & 413.5 & 400.5 & 400.5 & 412.5 \\
\hline
\end{tabular}

TABLE 6: Transportation times between the first and the second transshipment terminals (hour/unit product).

\begin{tabular}{lcccccc}
\hline & & Marport & Gemlik & Akport & LSP Port & Haydarpaşa \\
\hline Cologne Railway Terminal & Railway & \multicolumn{3}{c}{ No transportation } & & 120.0 \\
Passau Railway Terminal & Railway & & & 339.0 & 333.0 & 333.0 \\
\hline Hamburg Port & Sea & 336.0 & 75.0 & 69.0 & 69.0 & 337.0 \\
Trieste Port & Sea & 72.0 & 73.0 \\
\hline
\end{tabular}

4.1. General Structure of the Proposed Alternative Transportation Network. Proposed methodology is applied to a fourechelon transportation network located between Turkey and Germany (Figure 5). Five types of product (A, B, C, D, and E) are demanded from Turkey and supplied from four different locations in Germany: Berlin, Cologne, Hannover, and Munich. Transshipment terminals are changed according to preferred transportation mode whether sea or railway mode. The first transportation alternative is direct transportation to a local warehouse and then to demand points in Turkey via road transportation without changing transportation mode at any transshipment terminal. If multimodal transportation is preferred, there are four different arrival points for the first echelon. First two arrival points provide the opportunity to continue with railway transportation and are located in Cologne Railway Terminal and Passau Railway Terminal (nearby Austrian border). The other two arrival points provide the opportunity to continue with sea transportation and are located in Hamburg Port (Germany) and Trieste Port (Italy). It is assumed that suppliers have connection to the railway or opportunity to use railway with an acceptable proximity. In the present case, transshipment terminals at the end of the first echelon can be reached via railway or road transportations.

If the first transshipment is realized for the railway transportation mode, the arrival point in Turkey would be Haydarpaşa Railway Terminal. If it is realized for the sea mode, arrival point would be one of the ports in Marmara Region selected via ANP: Marport, Haydarpaşa, Akport, or Gemport Ports. Port selection process is detailed in the following section. LSP's investment to its own port is also considered as another alternative. In such a situation, most convenient location is found as Tekirdağ and this location is considered as a fifth port alternative. Arrivals via sea or railway modes to the importer country, Turkey, may be transferred to local warehouses located in Çerkezköy, Kocaeli, and Eskişehir via railway or road transportation. Transportation may be realized from local warehouses, ports, and Haydarpaşa Railway Terminal to demand points located in Ankara, Canakkale, Bandırma, Edirne, Bolu, Afyon, and Bursa via road transportation mode.

4.2. Evaluating Transportation Modes and Port Alternatives. Cost and time data and coefficients obtained via the ANP are used to solve the proposed model. Required data is obtained via interviews with experts from logistics sector, container ports, LSPs, and Internet resources of the logistic companies and government agencies in Turkey and Germany. While proposed model is a general one, application results are company specific changing according to the used data and investigating transportation project.

In the transportation modes evaluation, 54 criteria in 9 criteria cluster which are product characteristics, cost, safety problems, traceability, risks, flexibility, reliability, incentives (tax and investment capital decreases), and speed are used. Details of the classification stage and definitions of the criteria can be found in Tuzkaya and Önüt [20]. After pairwise comparisons of the criteria in each cluster and between clusters, overall weights of them are obtained as product characteristics $12.3 \%$, cost $16.9 \%$, safety problems $7.5 \%$, traceability 
TABle 7: Transportation costs from the second transshipment terminals to local warehouses and demand points in Turkey (TL/product).

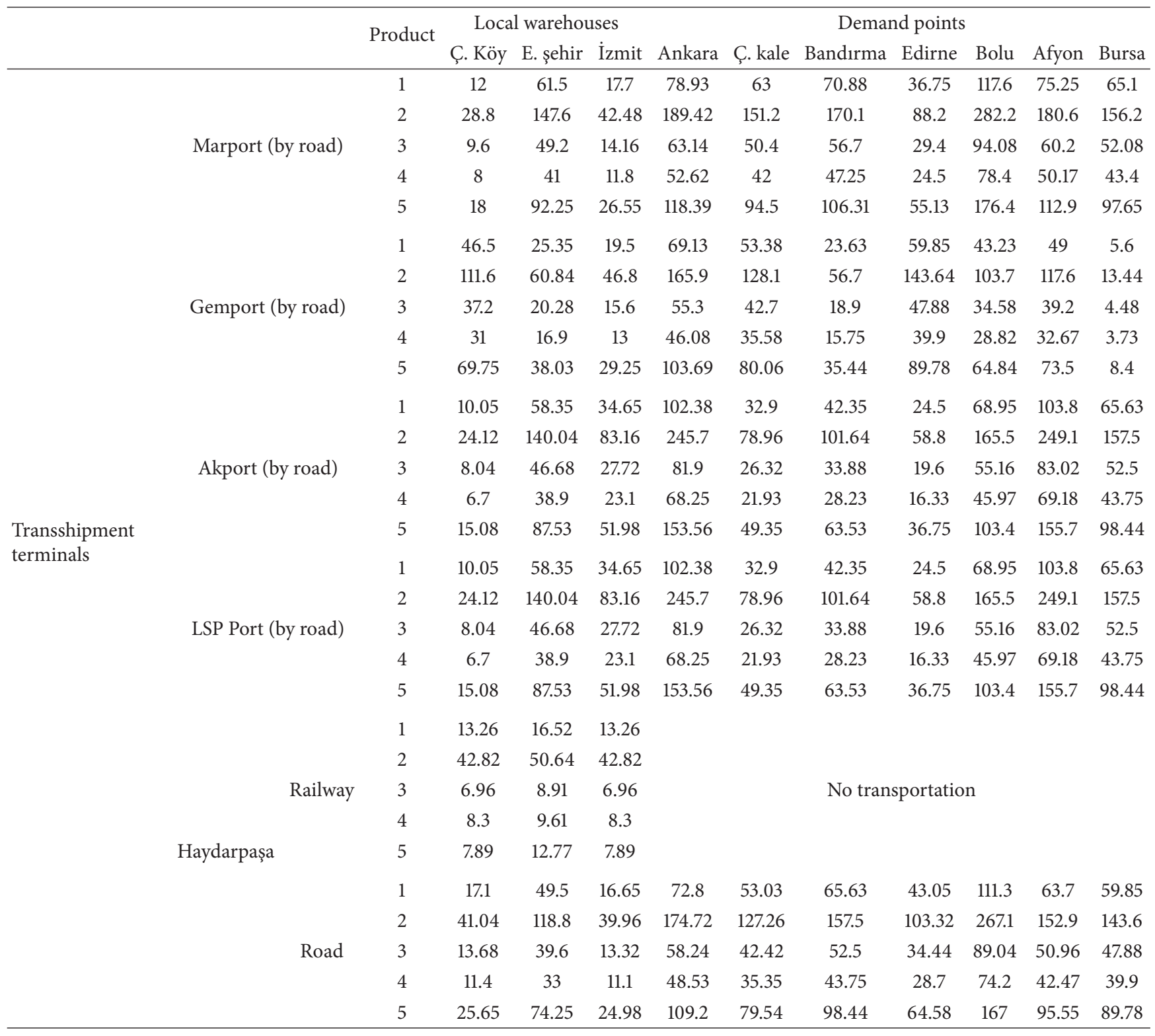

$4.6 \%$, risks $12.6 \%$, flexibility $15.4 \%$, reliability $9.2 \%$, incentives $13.8 \%$, and speed $7.7 \%$.

It is clearly seen that even there is not significant differences between the criteria cluster weights, the most important ones are cost, flexibility, and incentives, respectively. Then alternative transportation modes are compared considering the criteria weights. Finally, weights of railway, sea, and road transportation modes are obtained as $0.369,0.405$, and 0.226 , respectively. Although the differences between weights of transportation mode alternatives are not very high, sea is chosen as the best transportation mode.

The ANP is also used for determining the alternative transshipment terminals in Marmara Region in Turkey. 20 criteria in 6 criteria clusters are determined considering the literature and opinions of the decision makers. After applying same solution procedure using the ANP, the weights of the criteria are obtained as location of the port $20.9 \%$, port productivity $14 \%$, hinterland economy $20.9 \%$, physical features of the port $18.6 \%$, cost $11.6 \%$, and other conditions $14 \%$.

The weights of the location of the port and hinterland economy criteria are equal and share the first position. When the calculation process is ended, 4 alternative ports are determined among 12 ports in Marmara Region: Marport, Gemport, Akport, and Haydarpaşa. Also a possible port investment of LSP is considered and the convenient place is determined as Tekirdağ near alternative point Akport. 
TABLE 8: Transportation costs from local warehouses to demand points (TL/product).

\begin{tabular}{|c|c|c|c|c|c|c|c|c|c|}
\hline & & \multirow{2}{*}{ Product } & \multicolumn{7}{|c|}{ Demand points } \\
\hline & & & Ankara & Ç. kale & Bandirma & Edirne & Bolu & Afyon & Bursa \\
\hline \multirow{15}{*}{ Local warehouses } & \multirow{5}{*}{ Çerkezköy (by road) } & 1 & 57.09 & 23.18 & 35.75 & 14.84 & 81.03 & 66.08 & 38.03 \\
\hline & & 2 & 137.02 & 55.64 & 85.8 & 35.62 & 194.48 & 158.6 & 91.26 \\
\hline & & 3 & 45.67 & 18.55 & 28.6 & 11.87 & 64.83 & 52.87 & 30.42 \\
\hline & & 4 & 38.06 & 15.46 & 23.83 & 9.89 & 54.02 & 44.06 & 25.35 \\
\hline & & 5 & 85.64 & 34.78 & 53.63 & 22.26 & 121.55 & 99.13 & 57.04 \\
\hline & \multirow{5}{*}{ Eskişehir (by road) } & 1 & 25.03 & 45.61 & 27.19 & 52.33 & 45.93 & 14.19 & 15.71 \\
\hline & & 2 & 60.06 & 109.46 & 65.26 & 125.58 & 110.24 & 34.06 & 37.7 \\
\hline & & 3 & 20.02 & 36.49 & 21.75 & 41.86 & 36.75 & 11.35 & 12.57 \\
\hline & & 4 & 16.68 & 30.41 & 18.13 & 34.88 & 30.62 & 9.46 & 10.47 \\
\hline & & 5 & 37.54 & 68.41 & 40.79 & 78.49 & 68.9 & 21.29 & 23.56 \\
\hline & \multirow{5}{*}{ İzmit (by road) } & 1 & 37.05 & 43.66 & 24.92 & 36.83 & 16.36 & 37.92 & 14.3 \\
\hline & & 2 & 88.92 & 104.78 & 59.8 & 88.4 & 39.26 & 91 & 34.32 \\
\hline & & 3 & 29.64 & 34.93 & 19.93 & 29.47 & 13.09 & 30.33 & 11.44 \\
\hline & & 4 & 24.7 & 29.11 & 16.61 & 24.56 & 10.91 & 25.28 & 9.53 \\
\hline & & 5 & 55.58 & 65.49 & 37.38 & 55.25 & 24.54 & 56.88 & 21.45 \\
\hline
\end{tabular}

TABLE 9: Railway and road transportation times in Turkey (hour/container).

\begin{tabular}{|c|c|c|c|c|c|c|c|c|c|c|c|c|}
\hline & & & \multicolumn{3}{|c|}{ Local warehouses } & \multicolumn{7}{|c|}{ Demand points } \\
\hline & & & Ç. köy & Eskişehir & İzmit & Ankara & Ç. kale & Bandirma & Edirne & Bolu & Afyon & Bursa \\
\hline \multirow{6}{*}{$\begin{array}{l}\text { Transshipment } \\
\text { terminals }\end{array}$} & \multicolumn{2}{|c|}{ Marport (by road) } & 2.00 & 6.00 & 3.00 & 9.00 & 6.00 & 8.00 & 7.00 & 4.50 & 9.00 & 7.50 \\
\hline & \multicolumn{2}{|c|}{ Gemlik (by road) } & 6.50 & 3.50 & 3.00 & 8.00 & 6.50 & 3.00 & 7.00 & 5.00 & 6.00 & 1.00 \\
\hline & \multicolumn{2}{|c|}{ Akport (by road) } & 1.50 & 8.00 & 5.00 & 12.00 & 4.00 & 5.00 & 3.00 & 8.00 & 12.00 & 7.50 \\
\hline & \multicolumn{2}{|c|}{ LSP Port (by road) } & 1.50 & 8.00 & 5.00 & 12.00 & 4.00 & 5.00 & 3.00 & 8.00 & 12.00 & 7.50 \\
\hline & \multirow{2}{*}{ Haydarpaşa } & Railway & 3.00 & 8.00 & 3.00 & \multicolumn{7}{|c|}{ No transportation } \\
\hline & & Road & 2.50 & 7.00 & 2.50 & 8.50 & 6.00 & 7.50 & 5.00 & 13.00 & 7.50 & 7.00 \\
\hline \multirow{3}{*}{ Local warehouses } & \multicolumn{2}{|c|}{ Çerkezköy (by road) } & \multirow{3}{*}{\multicolumn{3}{|c|}{ No transportation }} & 11.00 & 4.50 & 7.00 & 3.00 & 15.00 & 12.50 & 7.00 \\
\hline & \multirow{2}{*}{\multicolumn{2}{|c|}{$\begin{array}{c}\text { Eskişehir (by road) } \\
\text { İmit (by road) }\end{array}$}} & & & & 5.00 & 8.50 & 5.00 & 10.00 & 8.50 & 3.00 & 3.00 \\
\hline & & & & & & 7.00 & 8.00 & 5.00 & 7.00 & 3.00 & 7.00 & 3.00 \\
\hline
\end{tabular}

4.3. Numerical Data Collection. A significant part of the numerical data is related with the unit transportation and unit transshipment costs and times among the points in transportation network. Most of the data are obtained by interviews with authorities of the logistics service providers and researches in their web sites.

Product based transportation costs $\left(\mathrm{CTr}_{\text {pila }}^{1}\right)$ from manufacturing facilities in Germany to local warehouses in Turkey are given in Table 1. Product based transportation times $\left(\operatorname{TTr}_{\text {pila }}^{1}\right)$ between the same points are given in Table 2 .

Product and transportation mode based transportation costs $\left(\mathrm{CTr}_{\text {pija }}^{2}\right)$ from four manufacturing facilities in Germany to railway and sea transshipment terminals in Germany and Italy are given in Table 3. Transportation times between the same points are given in Table $4\left(\mathrm{TTr}_{\text {pija }}^{2}\right)$.

Product and transportation mode based transportationcosts $\left(\mathrm{CTr}_{p j k a}^{3}\right)$ from four transshipment terminals in
Germany and Italy to one railway terminal and five ports in Turkey are given in Table 5. Product and transportation mode based transportation times $\left(\operatorname{TTr}_{p j k a}^{3}\right)$ between the same points are given in Table 6.

Product and transportation mode based transportation costs from the second transshipment terminals to demand points $\left(\mathrm{CTr}_{p k m a}^{4}\right)$ and local warehouses $\left(\mathrm{CTr}_{p k l a}^{5}\right)$ are in Table 7 and from local warehouses to demand points $\left(\mathrm{CTr}_{\text {plma }}^{6}\right)$ are in Table 8. Product and transportation mode based transportation times $\left(\mathrm{TTr}_{p k m a}^{4}, \mathrm{TTr}_{p k l a}^{5}, \mathrm{TTr}_{p l m a}^{6}\right)$ between the same locations are given in Table 9 .

Table 10 presents the unloading costs $\left(\mathrm{CTrns} s_{p j a}^{J \text {,unload }}\right)$, warehousing costs $\left(\mathrm{CWhs}_{p j a}^{J}\right.$ ), and loading costs ( $\mathrm{CTrns}_{p j a}^{J, \text { load }}$ ) depending on transportation mode alternatives for the first transshipment terminals. Table 11 presents unloading times $\left(\mathrm{TTrns} s_{p j a}^{J \text {,unload }}\right)$, warehousing times $\left(\mathrm{TWhs}_{p j a}^{J}\right)$, and loading 
TABLE 10: Product based unloading, warehousing, and loading costs in the first transshipment terminals (TL/product).

\begin{tabular}{|c|c|c|c|c|c|}
\hline & Product & Cologne Railway Terminal & Hamburg Port & Passau Railway Terminal & Trieste Port \\
\hline \multirow{5}{*}{$\begin{array}{l}\text { Unloading cost of products } \\
\text { transported by railway }\end{array}$} & 1 & 6.68 & 11.13 & 5.19 & 10.38 \\
\hline & 2 & 16.02 & 26.7 & 12.46 & 24.92 \\
\hline & 3 & 5.34 & 8.9 & 4.15 & 8.31 \\
\hline & 4 & 4.45 & 7.42 & 3.46 & 6.92 \\
\hline & 5 & 10.01 & 16.69 & 7.79 & 15.58 \\
\hline \multirow{5}{*}{$\begin{array}{l}\text { Unloading cost of products } \\
\text { transported by road }\end{array}$} & 1 & 6.68 & 11.13 & 5.19 & 10.38 \\
\hline & 2 & 16.02 & 26.7 & 12.46 & 24.92 \\
\hline & 3 & 5.34 & 8.9 & 4.15 & 8.31 \\
\hline & 4 & 4.45 & 7.42 & 3.46 & 6.92 \\
\hline & 5 & 10.01 & 16.69 & 7.79 & 15.58 \\
\hline \multirow{5}{*}{$\begin{array}{l}\text { Waiting cost of products } \\
\text { transported by road }\end{array}$} & 1 & 7.42 & 2.97 & 2.97 & 2.97 \\
\hline & 2 & 17.8 & 7.12 & 7.12 & 7.12 \\
\hline & 3 & 5.93 & 2.37 & 2.37 & 2.37 \\
\hline & 4 & 4.94 & 1.98 & 1.98 & 1.98 \\
\hline & 5 & 11.13 & 4.45 & 4.45 & 4.45 \\
\hline \multirow{5}{*}{$\begin{array}{l}\text { Waiting cost of products } \\
\text { transported by railway }\end{array}$} & 1 & 7.42 & 2.97 & 2.97 & 2.97 \\
\hline & 2 & 17.8 & 7.12 & 7.12 & 7.12 \\
\hline & 3 & 5.93 & 2.37 & 2.37 & 2.37 \\
\hline & 4 & 4.94 & 1.98 & 1.98 & 1.98 \\
\hline & 5 & 11.13 & 4.45 & 4.45 & 4.45 \\
\hline \multirow{5}{*}{$\begin{array}{l}\text { Loading cost of products } \\
\text { for railway transport }\end{array}$} & 1 & 6.68 & & 5.19 & \\
\hline & 2 & 16.02 & & 12.46 & \\
\hline & 3 & 5.34 & No transportation & 4.15 & No transportation \\
\hline & 4 & 4.45 & & 3.46 & \\
\hline & 5 & 10.01 & & 7.79 & \\
\hline \multirow{5}{*}{$\begin{array}{l}\text { Loading cost of products } \\
\text { for sea transport }\end{array}$} & 1 & & 20.03 & & 17.8 \\
\hline & 2 & & 48.06 & & 42.72 \\
\hline & 3 & No transportation & 16.02 & No transportation & 14.24 \\
\hline & 4 & & 13.35 & & 11.87 \\
\hline & 5 & & 30.04 & & 26.7 \\
\hline
\end{tabular}

TABLE 11: Unloading, warehousing, and loading times in the first transshipment terminals (hours/container).

\begin{tabular}{lcccc}
\hline & $\begin{array}{c}\text { Cologne Railway } \\
\text { Terminal }\end{array}$ & Hamburg Port & $\begin{array}{c}\text { Passau Railway } \\
\text { Terminal }\end{array}$ & Trieste Port \\
\hline Unloading time of products transported by railway & 2 & 3 & 2 & 3 \\
Unloading time of products transported by road & 1 & 2 & 36 & 36 \\
Waiting time of products transported by road or sea & 48 & No transportation & 2.5 & No transportation \\
Loading time of products for railway transport & 3 & 6 & No transportation \\
Loading time of products for sea transport & No transportation & & 5 \\
\hline
\end{tabular}

times (TTrns ${ }_{\text {pja }}^{\text {,load }}$ ) depending on transportation mode alternatives for the same terminals.

Table 12 presents the unloading costs $\left(\mathrm{CTrns}_{p k a}^{K \text {,unload }}\right)$, warehousing costs $\left(\mathrm{CWhs}_{p k a}^{K}\right)$, and loading costs $\left(\mathrm{CTrns}{ }_{p k a}^{K, \text { load }}\right.$ ) depending on transportation mode alternatives for the second transshipment terminals. Table 13 presents unloading times (TTrns ${ }_{p k a}^{K \text {,unload }}$ ), warehousing times $\left(\mathrm{TWhs}_{p k a}^{K}\right.$ ) and loading times (TTrns ${ }_{p k a}^{K, \text { load }}$ ) depending on transportation mode alternatives for the same terminals.

Table 14 presents the unloading costs (CTrns $s_{\text {pla }}^{L \text {,unload }}$ ), warehousing costs $\left(\mathrm{CWhs}_{\text {pla }}^{L}\right)$, and loading costs (CTrns ${ }_{\text {pla }}^{L, \text { load }}$ ) depending on transportation mode alternatives for 
TABLE 12: Product based unloading, warehousing, and loading costs in the second transshipment terminals (TL/product).

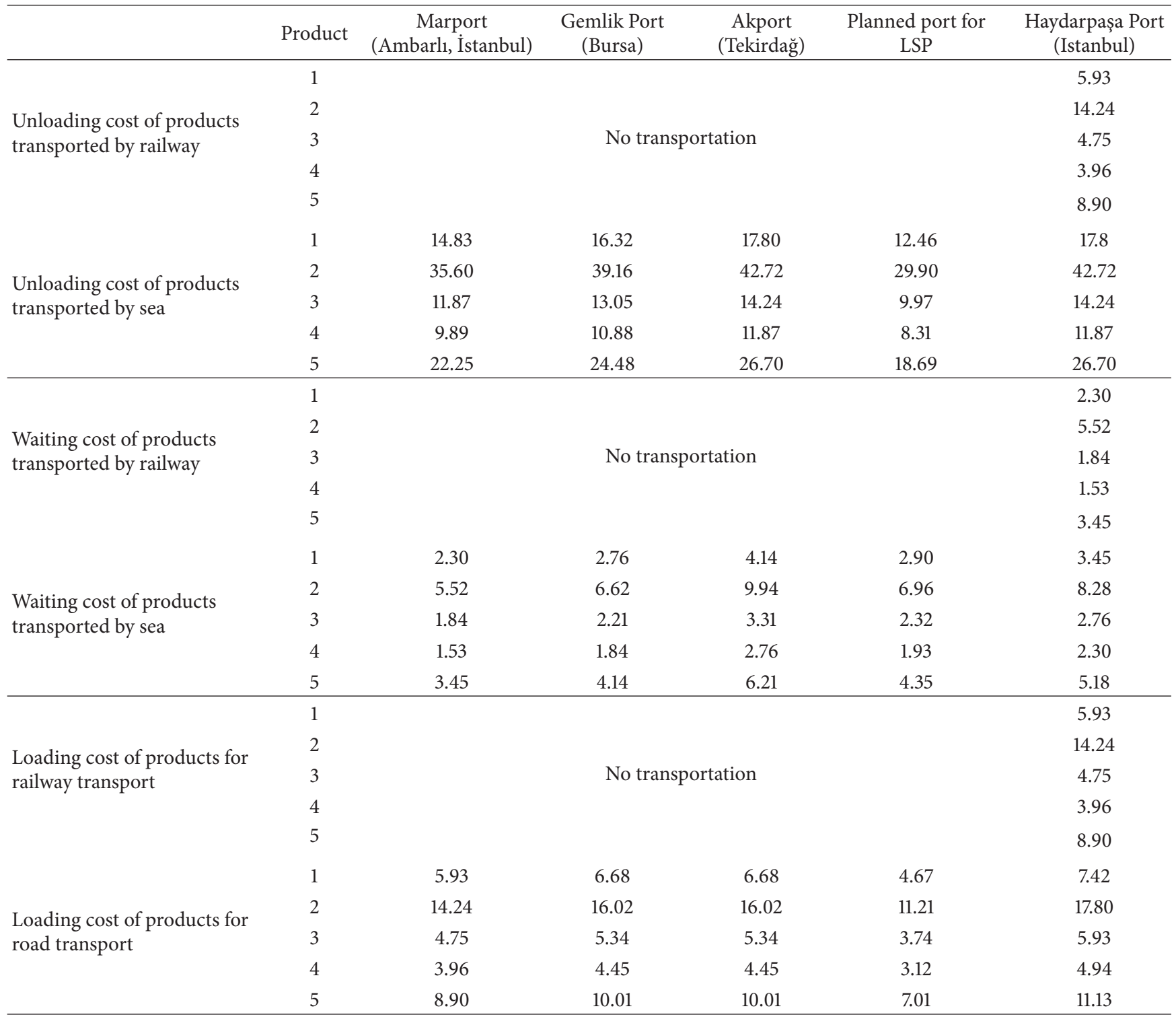

TABLE 13: Unloading, warehousing, and loading times in the second transshipment terminals (hours/container).

\begin{tabular}{|c|c|c|c|c|c|}
\hline & $\begin{array}{c}\text { Marport } \\
\text { (Ambarlı, İstanbul) }\end{array}$ & $\begin{array}{c}\text { Gemlik Port } \\
\text { (Bursa) }\end{array}$ & $\begin{array}{c}\text { Akport } \\
\text { (Tekirdağ) }\end{array}$ & $\begin{array}{l}\text { Planned port } \\
\text { for LSP }\end{array}$ & $\begin{array}{c}\text { Haydarpaşa Port } \\
\text { (Istanbul) }\end{array}$ \\
\hline Unloading cost of products transported by railway & \multicolumn{4}{|c|}{ No transportation } & 12 \\
\hline Unloading cost of products transported by sea & 1 & 1 & 1 & 0.7 & 2 \\
\hline Waiting cost of products transported by railway & \multicolumn{4}{|c|}{ No transportation } & 48 \\
\hline Waiting cost of products transported by sea & 48 & 48 & 72 & 50.4 & 72 \\
\hline Loading cost of products for railway transport & \multicolumn{4}{|c|}{ No transportation } & 3 \\
\hline Loading cost of products for road transport & 2 & 3 & 3 & 2.1 & 4 \\
\hline
\end{tabular}


TABLE 14: Product based unloading, warehousing, and loading costs in local warehouses (TL/product).

\begin{tabular}{|c|c|c|c|c|}
\hline & Product & $\begin{array}{c}\text { Çerkezköy } \\
\text { Local Warehouse }\end{array}$ & $\begin{array}{c}\text { Eskişehir } \\
\text { Local Warehouse }\end{array}$ & $\begin{array}{c}\text { İzmit } \\
\text { Local Warehouse }\end{array}$ \\
\hline \multirow{5}{*}{ Unloading cost of products transported by railway } & 1 & 7.42 & 8.90 & 8.16 \\
\hline & 2 & 17.80 & 21.36 & 19.58 \\
\hline & 3 & 5.93 & 7.12 & 6.53 \\
\hline & 4 & 4.94 & 5.93 & 5.44 \\
\hline & 5 & 11.13 & 13.35 & 12.24 \\
\hline \multirow{5}{*}{ Unloading cost of products transported by road } & 1 & 4.45 & 5.93 & 5.19 \\
\hline & 2 & 10.68 & 14.24 & 12.46 \\
\hline & 3 & 3.56 & 4.75 & 4.15 \\
\hline & 4 & 2.97 & 3.96 & 3.46 \\
\hline & 5 & 6.68 & 8.90 & 7.79 \\
\hline \multirow{5}{*}{ Waiting cost of products transported by road } & 1 & 1.48 & 1.78 & 1.48 \\
\hline & 2 & 3.56 & 4.27 & 3.56 \\
\hline & 3 & 1.19 & 1.42 & 1.19 \\
\hline & 4 & 0.99 & 1.19 & 0.99 \\
\hline & 5 & 2.23 & 2.67 & 2.23 \\
\hline \multirow{5}{*}{ Waiting cost of products transported by railway } & 1 & 2.23 & 2.67 & 2.23 \\
\hline & 2 & 5.34 & 6.41 & 5.34 \\
\hline & 3 & 1.78 & 2.14 & 1.78 \\
\hline & 4 & 1.48 & 1.78 & 1.48 \\
\hline & 5 & 3.34 & 4.01 & 3.34 \\
\hline \multirow{5}{*}{ Loading cost of products for road transport } & 1 & 4.45 & 5.93 & 5.19 \\
\hline & 2 & 10.68 & 14.24 & 12.46 \\
\hline & 3 & 3.56 & 4.75 & 4.15 \\
\hline & 4 & 2.97 & 3.96 & 3.46 \\
\hline & 5 & 6.68 & 8.90 & 7.79 \\
\hline
\end{tabular}

TABLE 15: Unloading, warehousing, and loading times in local warehouses (hours/container).

\begin{tabular}{lccc}
\hline & Çerkezköy Local Warehouse & Eskişehir Local Warehouse & İzmit Local Warehouse \\
\hline Unloading cost of products transported by railway & 3 & 4 & 3 \\
Unloading cost of products come by road & 2 & 3 & 2 \\
Waiting cost of products come by road & 24 & 24 & 24 \\
Waiting cost of products come by railway & 36 & 36 & 36 \\
Loading cost of products for road transport & 2 & 3 & 2 \\
\hline
\end{tabular}

TABLE 16: Physical features of the demanded products.

\begin{tabular}{lccc}
\hline Product & $\begin{array}{c}\text { Weight } \\
\text { (ton) }\end{array}$ & $\begin{array}{c}\text { Max number of } \\
\text { products transported } \\
\text { by a container }\end{array}$ & $\begin{array}{c}\text { Volume of each } \\
\text { product (percentage of } \\
\text { the container) }\end{array}$ \\
\hline 1 & 0.5 & 12 & $8 \%$ \\
2 & 1.2 & 5 & $20 \%$ \\
3 & 0.3 & 15 & $7 \%$ \\
4 & 0.2 & 18 & $6 \%$ \\
5 & 0.75 & 8 & $13 \%$ \\
\hline
\end{tabular}

local warehouses. Table 15 presents unloading times $\left(\mathrm{TTrns}_{\text {pla }}^{L \text {,unload }}\right)$, warehousing times (TWhs ${ }_{\text {pla }}^{L}$ ), and loading times (TTrns pla $_{\text {Lload }}$ ) depending on transportation mode alternatives for the same warehouses.

In addition to the transportation and warehousing costs and time data, product related data is also required for the model. Physical features, like volume and weight, and demand quantities are gathered from LSP and its main producers as the approximate values. The chosen products are finished goods and spare parts for automotive sector and they can be containerized for multimodal transportation. Table 16 gives weight and volume data of the products considering the container capacity.

Total demand quantities of the demand points, which are located in the seven different points in Turkey, are predicted as 40000 containers for 5 years which means approximately 
TABLE 17: Product based demand quantities of the demand points (unit).

\begin{tabular}{lcccccc}
\hline Demand points & Product 1 & Product 2 & Product 3 & Product 4 & Product 5 & Number of required containers \\
\hline Ankara & 28000 & 6000 & 1200 & 12200 & 2400 & 4591 \\
Çanakkale & 0 & 10000 & 5600 & 8600 & 0 & 2851 \\
Bandırma & 18400 & 12000 & 15400 & 10800 & 0 & 5560 \\
Edirne & 13600 & 8000 & 0 & 600 & 10800 & 4117 \\
Bolu & 26000 & 24000 & 13000 & 20000 & 14400 & 10744 \\
Afyon & 28800 & 6000 & 13400 & 8400 & 1000 & 5085 \\
Bursa & 33200 & 14000 & 5400 & 11400 & 3400 & 6985 \\
\hline
\end{tabular}

TABLE 18: Container capacities of each echelon.

\begin{tabular}{|c|c|c|c|c|c|}
\hline First transshipment terminal & Container capacity & $\begin{array}{l}\text { Second transshipment } \\
\text { terminal }\end{array}$ & $\begin{array}{c}\text { Container } \\
\text { capacity }\end{array}$ & $\begin{array}{c}\text { Local } \\
\text { warehouses }\end{array}$ & $\begin{array}{c}\text { Container } \\
\text { capacity }\end{array}$ \\
\hline Cologne Railway Terminal & 22000 & Marport & 30000 & Çerkezköy & 27000 \\
\hline Hamburg Port & 20000 & Gemlik & 27000 & Eskişehir & 28000 \\
\hline Passau Railway Terminal & 35000 & Akport & 28000 & İzmit & 22000 \\
\hline \multirow[t]{2}{*}{ Trieste Port } & 28000 & Haydarpaşa Port & 35000 & & \\
\hline & & Planned port for LSP & 40000 & & \\
\hline
\end{tabular}

8000 containers for each year. Distribution of this total amount among the demand points $\left(D_{p m}\right)$ is given in Table 17. The last column of Table 17 shows the required container number to meet the entire demand of the demand points for the total of all product types.

Some production restrictions are also included in the model, since each supplier in Germany cannot produce all product types. Product 1 can be produced in manufacturing facilities 2 or 4 . Products 2, 3, and 4 are produced in only manufacturing facilities 1,3 , and 4 , respectively. Product 5 can be produced in manufacturing facility 2 or 3 .

Another data group is related to the investment and operating costs of the planned investments for the second transshipment terminals and local warehouse echelons. These echelons are chosen for port and warehouse investments considering the sector-specific applications as mentioned previously. After the series of interviews with the authorities in the sector, Tekirdağ is selected as the most proper place for a port investment and Çerkezköy, Eskişehir, and Izmit are selected as the local warehouse investment points. Many cost items and expenses even some of which cannot be predictable are calculated to determine the investment and operating cost.

A port with a capacity of 80000 containers per year is planned to be built and $10 \%$ part of it is assigned to this project. $\$ 2000000$ as investment cost and $\$ 500000$ as the annual operating cost will be charged but loading, warehousing, and unloading costs will decrease 30\% whether it is opened. For the local warehouses in Çerkezköy, Eskişehir, and Izmit, 800000 TL, 600000 TL, and 700000 TL investment costs and $170000 \mathrm{TL}, 145000 \mathrm{TL}$, and $155000 \mathrm{TL}$ operation costs will be required, respectively.

The last data group is related with the container capacities of the first and second transshipment terminals and the local warehouses that are given in Table 18.
4.4. Solving the Model by Using Fuzzy Programming Approach. To solve the multilevel and multiobjective decentralized problem with fuzzy programming approach, the membership functions for each objective of the related level's decision maker are built. For the calculation of membership functions, it is necessary to determine the best and worst values that the objective functions may get. Therefore, the model is solved considering each objective function separately. The obtained values for decision variables are used in the remaining objectives as explained in Section 3.2. Table 19 shows the obtained objective function results for each different value of decision variables.

When the transported products are considered, it is seen that the products are transported by railway from all manufacturing facilities to the first transshipment terminals, except to Cologne Railway Terminal (Table 20). Most of the products are transported to Trieste Port (entire of products 1 , 3,4 , and certain part of the product 5).

Also the products can be transported from manufacturing facilities to local warehouses and Table 21 shows the direct transportations from Berlin and Munich to İzmit Local Warehouse by road transportation mode.

For the long haul between the first and second transshipment terminals, both railway and sea transportation modes are used (Table 22). The products are transported from Hamburg and Trieste Ports to Marport and Gemlik Port by sea. Besides, railway transportations are realized from Passau to Haydarpaşa Railway Terminal. No product is transported to Planned Port for LSP, since it is not found feasible to open.

According to the results, only one of the three local warehouses in İzmit is chosen for warehouse investment (Table 23). The certain part of the products is transported by using this local warehouse (Table 24). The remaining quantity 
TABLE 19: The obtained objective function values for different decision variable values.

\begin{tabular}{lccccc}
\hline & Objective function & 1 & 2 & 3 \\
\hline 1 & Maximization of total efficiency of transportation mode usage & $\mathbf{5 1 8 1 3 1 . 8 0}$ & 263932994.93 & 222234097.96 & 35728896.98 \\
2 & Total cost minimization & 465213.36 & $\mathbf{2 2 7 1 0 4 0 5 8 . 8 8}$ & 196343431.64 & 24790627.25 \\
3 & Total transportation costs minimization & 449097.84 & 228187951.37 & $\mathbf{1 9 4 7 2 2 5 3 7 . 9 7}$ & 27495413.39 \\
4 & Total transshipment costs & 180339.20 & 269793897.89 & 258626772.56 & 5197125.33 \\
5 & Facility establishment and operating costs minimization & 380040.40 & 250496246.20 & 226681286.84 & 23814959.36 \\
6 & Total time minimization & 180339.20 & 260499677.23 & 248918413.14 & 5611264.09 \\
7 & Total transportation time minimization & 180339.20 & 262363968.83 & 250650082.87 & 5743885.96 \\
8 & Total transshipment and storage time minimization & 180339.20 & 265983512.77 & 254730492.54 & 5283020.22 \\
\hline & & 5 & 6 & 7 \\
\hline 1 & Maximization of total efficiency of transportation mode usage & 5970000.00 & 140562750.00 & 76680750.00 & 63882000.00 \\
2 & Total cost minimization & 5970000.00 & 126132540.00 & 71893500.00 & 54239040.00 \\
3 & Total transportation costs minimization & 5970000.00 & 128325000.00 & 75726500.00 & 52598500.00 \\
4 & Total transshipment costs & 5970000.00 & 31702400.00 & 20894400.00 & 10808000.00 \\
5 & Facility establishment and operating costs minimization & $\mathbf{0}$ & 103960900.00 & 63184100.00 & 40776800.00 \\
6 & Total time minimization & 5970000.00 & $\mathbf{3 0 5 2 5 1 9 0 . 0 0}$ & 19589990.00 & 10935200.00 \\
7 & Total transportation time minimization & 5970000.00 & 30587350.00 & $\mathbf{1 9 5 6 4 5 5 0 . 0 0}$ & 11022800.00 \\
8 & Total transshipment and storage time minimization & 5970000.00 & 31606100.00 & 20798100.00 & $\mathbf{1 0 8 0 8 0 0 0 . 0 0}$ \\
\hline
\end{tabular}

The bold written values in each column are the optimum results of the related objective function. Considering these optimum values together with the worst values of the each column, membership functions are calculated only for objective functions. Tolerance values for decision variables are not calculated since each decision maker is interested in the entire decision variables not a specific part. The model is coded and solved by using GAMS 21.6 package program.

TABLE 20: Transportation quantities from manufacturing facilities to the first transshipment terminals.

\begin{tabular}{|c|c|c|c|c|c|c|c|}
\hline \multirow[b]{2}{*}{$\begin{array}{l}\text { Manufacturing } \\
\text { facilities }\end{array}$} & \multirow[b]{2}{*}{ Product } & \multirow[b]{2}{*}{$\begin{array}{l}\text { Transportation } \\
\text { mode }\end{array}$} & \multicolumn{4}{|c|}{ First transshipment terminals } & \multirow[b]{2}{*}{ Total } \\
\hline & & & $\begin{array}{c}\text { Cologne Railway } \\
\text { Terminal }\end{array}$ & $\begin{array}{c}\text { Hamburg } \\
\text { Port }\end{array}$ & $\begin{array}{c}\text { Passau Railway } \\
\text { Terminal } \\
\end{array}$ & Trieste Port & \\
\hline \multirow{2}{*}{ (1) Berlin } & \multirow{2}{*}{2} & Road & 0 & 0 & 0 & 0 & 0 \\
\hline & & Railway & 0 & 8401.108 & 20107.714 & 0 & 28508.822 \\
\hline \multirow{4}{*}{ (2) Munich } & \multirow{2}{*}{1} & Road & 0 & 0 & 0 & 0 & 0 \\
\hline & & Railway & 0 & 0 & 0 & 111560 & 111560 \\
\hline & \multirow{2}{*}{5} & Road & 0 & 0 & 0 & 0 & 0 \\
\hline & & Railway & 0 & 0 & 17800 & 14200 & 32000 \\
\hline \multirow{2}{*}{ (3) Hannover } & \multirow{2}{*}{3} & Road & 0 & 0 & 0 & 0 & 0 \\
\hline & & Railway & 0 & 0 & 0 & 54000 & 54000 \\
\hline \multirow{3}{*}{ (4) Cologne } & \multirow{3}{*}{4} & Road & 0 & 0 & 0 & 0 & 0 \\
\hline & & Railway & 0 & 0 & 0 & 72000 & 72000 \\
\hline & & Total & 0 & 8401.108 & 37907.714 & 251760 & 298068.82 \\
\hline
\end{tabular}

is transported from the second transshipment terminals to demand point by road directly (Table 25 ).

The overall satisfaction degree is found as $54.8 \%$. The satisfaction degrees and the obtained values of the objective functions are given in Table 26.

\section{Conclusions}

Particularly for the complicated, long distanced, and geographically wide spread international transportation activities, various types of products are consolidated in containers and generally transported between different echelons while arriving at the final destination. For each echelon, different transportation modes are utilized considering various criteria. Also, LSPs employs lots of decision makers from different hierarchical levels to cope with this complicated problem. Since, it is aimed to consider as much as possible factor in the model, the number of related decision makers increased. More satisfactory results can be obtained with the contribution of not only top management but also decision makers from the different departments and hierarchies.

Considering the above mentioned reasons, for the planning process of multimodal transportation systems, decentralized multilevel programming approach is utilized. 
TABLE 21: Transportation quantities from manufacturing facilities to local warehouses.

\begin{tabular}{|c|c|c|c|c|c|c|}
\hline \multirow{2}{*}{ Manufacturing facilities } & \multirow{2}{*}{ Product } & \multirow{2}{*}{ Transportation mode } & \multicolumn{3}{|c|}{ Local warehouses } & \multirow{2}{*}{ Total } \\
\hline & & & Çerkezköy & Eskişehir & İzmit & \\
\hline (1) Berlin & 2 & Road & 0 & 0 & 51491.178 & 51491.18 \\
\hline \multirow[t]{2}{*}{ (2) Munich } & 1 & Road & 0 & 0 & 36443.071 & 36443.07 \\
\hline & & Toplam & $\mathbf{0}$ & $\mathbf{0}$ & 87934.249 & 87934.25 \\
\hline
\end{tabular}

TABLE 22: Transportation quantities from the first transshipment terminals to the second transshipment terminals.

\begin{tabular}{|c|c|c|c|c|c|c|c|c|}
\hline \multirow[b]{2}{*}{$\begin{array}{l}\text { First transshipment } \\
\text { points }\end{array}$} & \multirow[b]{2}{*}{ Product } & \multirow[b]{2}{*}{$\begin{array}{l}\text { Transportation } \\
\text { mode }\end{array}$} & \multicolumn{5}{|c|}{ Second transshipment terminals } & \multirow[b]{2}{*}{ Total } \\
\hline & & & Marport & Gemlik Port & Akport & $\begin{array}{c}\text { Haydarpaşa } \\
\text { Port }\end{array}$ & $\begin{array}{l}\text { Planned port } \\
\text { for LSP }\end{array}$ & \\
\hline \multirow{2}{*}{ (2) Hamburg Port } & \multirow{2}{*}{2} & Railway & 0 & 0 & 0 & 0 & 0 & 0 \\
\hline & & Sea & 0 & 8401.108 & 0 & 0 & 0 & 8401.108 \\
\hline \multirow{4}{*}{$\begin{array}{l}\text { (3) Passau Railway } \\
\text { Terminal }\end{array}$} & \multirow{2}{*}{2} & Railway & 0 & 0 & 0 & 20107.714 & 0 & 20107.71 \\
\hline & & Sea & 0 & 0 & 0 & 0 & 0 & 0 \\
\hline & \multirow{2}{*}{5} & Railway & 0 & 0 & 0 & 17800 & 0 & 17800 \\
\hline & & Sea & 0 & 0 & 0 & 0 & 0 & 0 \\
\hline \multirow{9}{*}{ (4) Trieste Port } & \multirow{2}{*}{1} & Railway & 0 & 0 & 0 & 0 & 0 & 0 \\
\hline & & Sea & 33453.984 & 78102.946 & 0 & 0 & 0 & 111556.9 \\
\hline & \multirow{2}{*}{3} & Railway & 0 & 0 & 0 & 0 & 0 & 0 \\
\hline & & Sea & 33200 & 20800 & 0 & 0 & 0 & 54000 \\
\hline & \multirow{2}{*}{4} & Railway & 0 & 0 & 0 & 0 & 0 & 0 \\
\hline & & Sea & 49800 & 22200 & 0 & 0 & 0 & 72000 \\
\hline & \multirow{3}{*}{5} & Railway & 0 & 0 & 0 & 0 & 0 & 0 \\
\hline & & Sea & 10800 & 3400 & 0 & 0 & 0 & 14200 \\
\hline & & Total & 127253.98 & 132904.05 & 0 & 37907.714 & 0 & 298065.8 \\
\hline
\end{tabular}

TABLE 23: Transportation quantities from the second transshipment terminals to local warehouses.

\begin{tabular}{|c|c|c|c|c|c|c|}
\hline \multirow{2}{*}{ Second transshipment terminals } & \multirow{2}{*}{ Product } & \multirow{2}{*}{ Transportation mode } & \multicolumn{3}{|c|}{ Local warehouses } & \multirow{2}{*}{ Total } \\
\hline & & & Çerkezköy & Eskişehir & İzmit & \\
\hline \multirow{3}{*}{ Marport } & 1 & Road & 0 & 0 & 19853.984 & 19853.98 \\
\hline & 3 & Road & 0 & 0 & 27600 & 27600 \\
\hline & 4 & Road & 0 & 0 & 49200 & 49200 \\
\hline \multirow{3}{*}{ Haydarpaşa Port } & \multirow{3}{*}{5} & Road & 0 & 0 & 0 & 0 \\
\hline & & Railway & 0 & 0 & 17800 & 17800 \\
\hline & & Total & 0 & 0 & 114453.98 & 114454 \\
\hline
\end{tabular}

TABLE 24: Transportation quantities from local warehouses to demand points.

\begin{tabular}{lccccccccccc}
\hline $\begin{array}{l}\text { Local } \\
\text { warehouses }\end{array}$ & \multirow{2}{*}{ Product } & \multirow{2}{*}{ Transportation mode } & \multicolumn{4}{c}{ Demand points } & \multicolumn{2}{c}{ Total } \\
& & & Ankara & Çanakkale & Bandirma & Edirne & Bolu & Afyon & Bursa \\
\hline \multirow{3}{*}{ İzmit } & 1 & Road & 28000 & 0 & 0 & 0 & 26000 & 2297.05 & 0 & 56297.054 \\
& 2 & Road & 6000 & 0 & 12000 & 0 & 24000 & 3892.29 & 5598.892 & 51491.178 \\
& 3 & Road & 1200 & 0 & 0 & 0 & 13000 & 13400 & 0 & 27600 \\
& 4 & Road & 12200 & 8600 & 0 & 0 & 20000 & 8400 & 0 & 49200 \\
& 5 & Road & 2400 & 0 & 0 & 0 & 14400 & 1000 & 0 & 17800 \\
\hline
\end{tabular}


TABLE 25: Transportation quantities from the second transshipment terminals to demand points.

\begin{tabular}{lcccccccccc}
\hline $\begin{array}{l}\text { Second transshipment } \\
\text { terminals }\end{array}$ & Product & $\begin{array}{c}\text { Transportation } \\
\text { mode }\end{array}$ & Ankara & Çanakkale & Bandırma & Edirne & Bolu & Afyon & Bursa \\
\hline \multirow{3}{*}{ Marport } & 1 & Road & 0 & 0 & 0 & 13600 & 0 & 0 & 0 \\
& 3 & Road & 0 & 5600 & 0 & 0 & 0 & 0 & 13600 \\
& 4 & Road & 0 & 0 & 0 & 600 & 0 & 0 & 0 & 600 \\
& 5 & Road & 0 & 0 & 0 & 10800 & 0 & 0 & 0 & 10800 \\
\hline \multirow{3}{*}{ Gemlik Port } & 1 & Road & 0 & 0 & 18400 & 0 & 0 & 26502.946 & 33200 & 78102.95 \\
& 2 & Road & 0 & 0 & 0 & 0 & 0 & 0 & 8401.108 & 8401.108 \\
& 3 & Road & 0 & 0 & 15400 & 0 & 0 & 0 & 5400 & 20800 \\
& 4 & Road & 0 & 0 & 10800 & 0 & 0 & 0 & 11400 & 22200 \\
Haydarpaşa Port & 5 & Road & 0 & 0 & 0 & 0 & 0 & 0 & 3400 & 3400 \\
\hline
\end{tabular}

In Tables 23, 24, and 25, the mentioned product quantities that are transported between echelons are depicted in Figure 6.

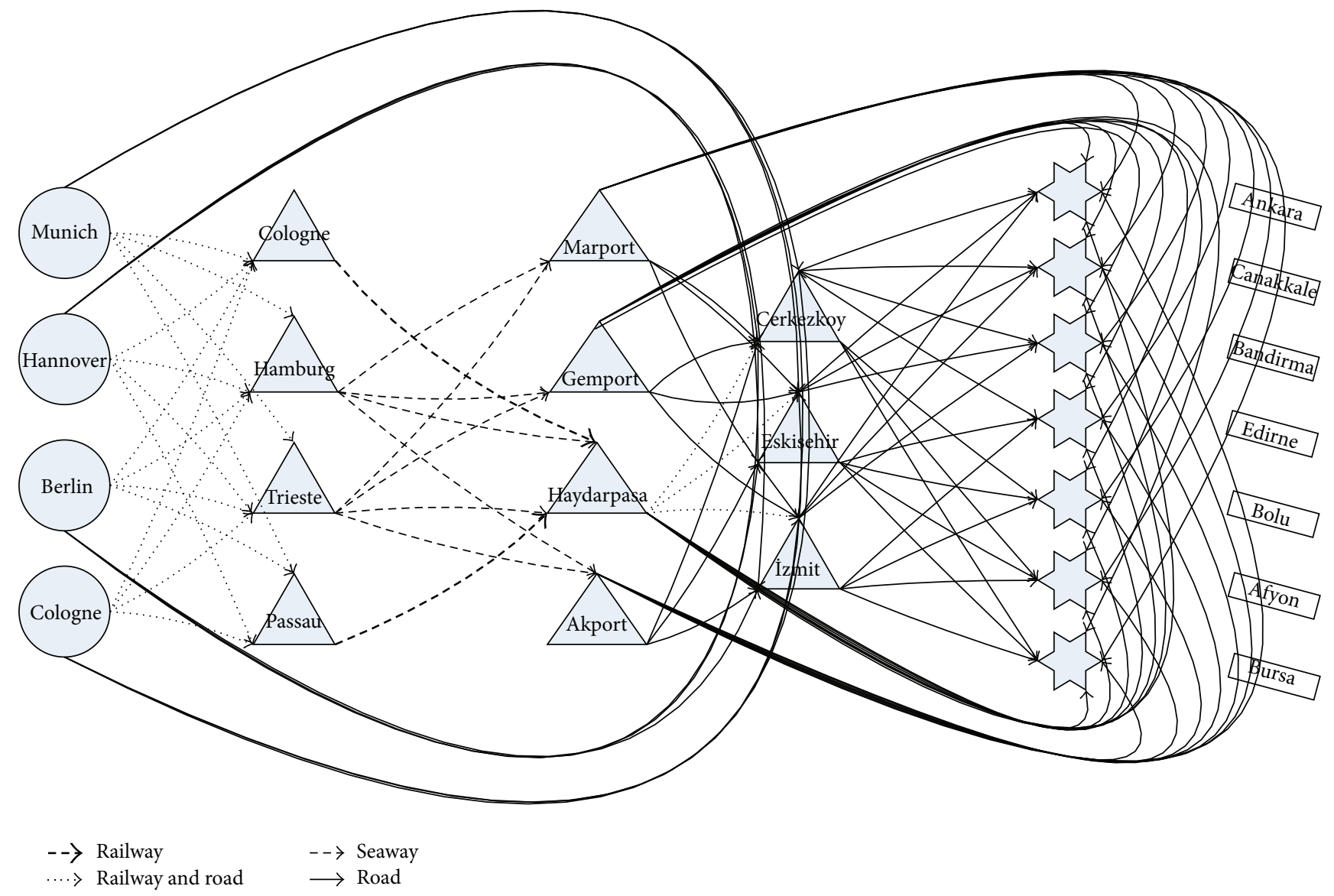

FIGURE 5: General structure of the current transportation network.

With the help of this approach, objectives of different departments and hierarchical levels of decision makers are tried to be optimized. As a result, the model is constituted with 8 conflicting or partially overlapping objective functions in three hierarchical levels.

Application of the model is realized based on a company's transportation activities using railway transportation for the long-distanced transportation between Germany and Turkey and road transportation for the short-distanced transportations. Not only current network's echelons and alternative locations are expanded but also considering the alternative transportation modes to be selected feasibility of potential investment alternatives of LSP is investigated. The aim of the model is to find convenient transportation modes and 


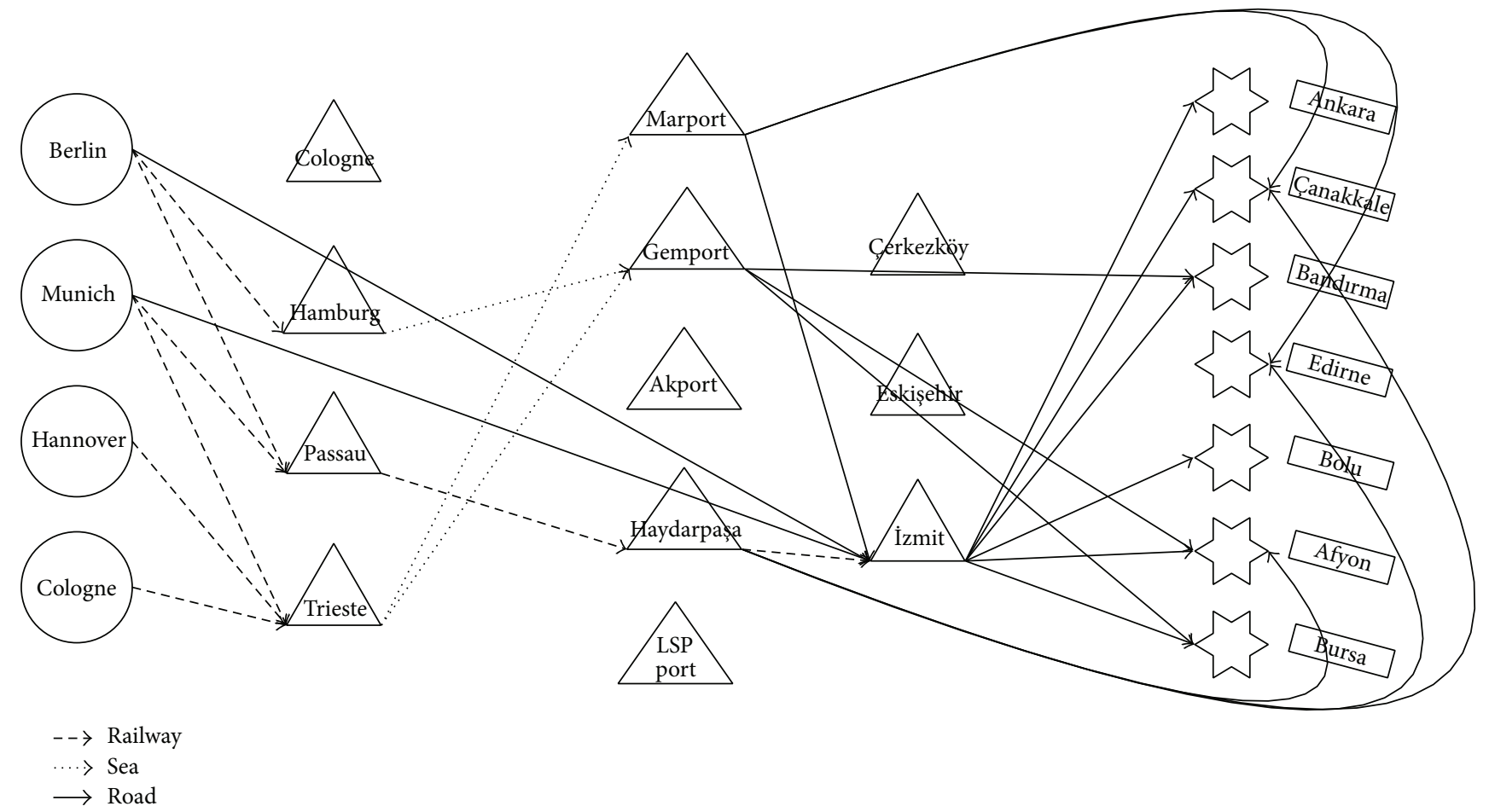

FiguRE 6: The obtained transportation network.

TABLE 26: Obtained objective function values and the satisfaction degrees.

\begin{tabular}{lcc}
\hline Objective function & Objective function value & Satisfaction degree \\
\hline 1 & 365440 & 0.548 \\
2 & 243460000 & 0.617 \\
3 & 223610000 & 0.548 \\
4 & 18998000 & 0.548 \\
5 & 855000 & 0.857 \\
6 & 69768000 & 0.643 \\
7 & 34969000 & 0.73 \\
8 & 34799000 & 0.548 \\
\hline
\end{tabular}

routes for different types of freights with the decision on transshipment terminals and local warehouses. Because of the number of the variables and constraints, it would not be possible to solve the model with classical optimization techniques and fuzzy logic is preferred to use.

One of the contributions of this paper is the transportation mode evaluation phase in which the number of the considered criteria is more than most of the literature. Another contribution is the consideration of objectives from different departments and hierarchical levels' decision makers. From the aspect of the real life applications, the advantage of the solution approach of the proposed model is that broad networks could be designed with no computational hardness.

It is important to apply a systematic methodology like proposed here at the establishment stage, for the important application problems of LSPs. For the transportation to the
European countries especially, most of the countries are setting transportation rules. Specifically for long-distanced transportation, alternatives to the road transportation are being intensive. Therefore, it may result in an inefficient situation to make a decision only with experiments; for example, selecting road alternative with solely consideration of time or selecting sea transportation alternative with solely consideration of cost may be inefficient and wrong decisions for the medium or long time periods. On the other hand, with the proposed methodology, plans about alternatives may be realized with the considerations of complicated relations and constraints.

Although, a specific problem is investigated in this study, the proposed model is a flexible one and if needed for other applications, the number of objective functions, variables, and constrains may be changed. For future studies complementary operators with the compensatory feature can be used to find alternative solutions for probable higher satisfaction levels. Then decision makers can evaluate and weight the subhierarchical level's objectives for the interactive and compromise solutions. Another future research may be realized with the consideration of the vagueness about the parameters in the constraints and objective functions. In this study, utilized data are obtained directly from the LSP and used in the model with their original forms. However, especially for the long-term decisions, there may be changes in the parameters' values and the vagueness about the parameters may be reflected using fuzzy numbers. 


\section{Conflict of Interests}

The authors declare that there is no conflict of interests regarding the publication of this paper.

\section{References}

[1] W. S. Chow, C. N. Madu, C. Kuei, M. H. Lu, C. Lin, and H. Tseng, "Supply chain management in the US and Taiwan: an empirical study," Omega, vol. 36, no. 5, pp. 665-679, 2008.

[2] C. Macharis and Y. M. Bontekoning, "Opportunities for OR in intermodal freight transport research: a review," European Journal of Operational Research, vol. 153, no. 2, pp. 400-416, 2004.

[3] B. Q. Rieksts and J. A. Ventura, "Optimal inventory policies with two modes of freight transportation," European Journal of Operational Research, vol. 186, no. 2, pp. 576-585, 2008.

[4] T. Chang, "Best routes selection in international intermodal networks," Computers and Operations Research, vol. 35, no. 9, pp. 2877-2891, 2008.

[5] C. Macharis and E. Pekin, "Assessing policy measures for the stimulation of intermodal transport: a GIS-based policy analysis," Journal of Transport Geography, vol. 17, no. 6, pp. 500508, 2009.

[6] J. Andersen, T. G. Crainic, and M. Christiansen, "Service network design with asset management: formulations and comparative analyses," Transportation Research C, vol. 17, no. 2, pp. 197-207, 2009.

[7] S.-W. Chiou, "A bi-level programming for logistics network design with system-optimized flows," Information Sciences, vol. 179, no. 14, pp. 2434-2441, 2009.

[8] J. C. Q. Dias, J. M. F. Calado, and M. C. Mendonça, “The role of European «ro-ro« port terminals in the automotive supply chain management," Journal of Transport Geography, vol. 18, no. 1, pp. 116-124, 2010.

[9] M. Verma and V. Verter, "A lead-time based approach for planning rail-truck intermodal transportation of dangerous goods," European Journal of Operational Research, vol. 202, no. 3, pp. 696-706, 2010.

[10] M. S. Pishvaee, R. Z. Farahani, and W. Dullaert, "A memetic algorithm for bi-objective integrated forward/reverse logistics network design," Computers \& Operations Research, vol. 37, no. 6, pp. 1100-1112, 2010.

[11] S. Bock, "Real-time control of freight forwarder transportation networks by integrating multimodal transport chains," European Journal of Operational Research, vol. 200, no. 3, pp. 733746, 2010.

[12] J. W. Jung and Y. H. Lee, "Heuristic algorithms for production and transportation planning through synchronization of a serial supply chain," International Journal of Production Economics, vol. 124, no. 2, pp. 433-447, 2010.

[13] P. Apivatanagul and A. C. Regan, "Long haul freight network design using shipper-carrier freight flow prediction: a California network improvement case study," Transportation Research E: Logistics and Transportation Review, vol. 46, no. 4, pp. 507$519,2010$.

[14] R. Ishfaq and C. R. Sox, "Intermodal logistics: the interplay of financial, operational and service issues," Transportation Research E: Logistics and Transportation Review, vol. 46, no. 6, pp. 926-949, 2010.
[15] M. Dotoli, M. P. Fanti, A. M. Mangini, G. Stecco, and W. Ukovich, "The impact of ICT on intermodal transportation systems: a modelling approach by Petri nets," Control Engineering Practice, vol. 18, no. 8, pp. 893-903, 2010.

[16] D. Song and J. Dong, "Effectiveness of an empty container repositioning policy with flexible destination ports," Transport Policy, vol. 18, no. 1, pp. 92-101, 2011.

[17] M. Feo, R. Espino, and L. García, "An stated preference analysis of Spanish freight forwarders modal choice on the south-west Europe Motorway of the Sea," Transport Policy, vol. 18, no. 1, pp. 60-67, 2011.

[18] Q. Meng and X. Wang, "Intermodal hub-and-spoke network design: incorporating multiple stakeholders and multi-type containers," Transportation Research B: Methodological, vol. 45, no. 4, pp. 724-742, 2011.

[19] G. Tuzkaya, S. Önüt, U. R. Tuzkaya, and B. Gülsün, "An analytic network process approach for locating undesirable facilities: an example from Istanbul, Turkey," Journal of Environmental Management, vol. 88, no. 4, pp. 970-983, 2008.

[20] U. R. Tuzkaya and S. Önüt, "A fuzzy analytic network process based approach to transportation-mode selection between Turkey and Germany: a case study," Information Sciences, vol. 178, no. 15, pp. 3133-3146, 2008.

[21] G. Tuzkaya, A. Ozgen, D. Ozgen, and U. R. Tuzkaya, "Environmental performance evaluation of suppliers: a hybrid fuzzy multi-criteria decision approach," International Journal of Environmental Science and Technology, vol. 6, no. 3, pp. 477-490, 2009.

[22] S. Onut, U. R. Tuzkaya, and E. Torun, "Selecting container port via a fuzzy ANP-based approach: a case study in the Marmara Region, Turkey," Transport Policy, vol. 18, no. 1, pp. 182-193, 2011.

[23] T. L. Saaty, Decision Making with Dependence and Feedback: The Analytic Network Process, RWS Publications, Pittsburgh, $\mathrm{Pa}$, USA, 1996.

[24] T. L. Saaty and L. G. Vargas, "Diagnosis with dependent symptoms: bayes theorem and the analytic hierarchy process," Operations Research, vol. 46, no. 4, pp. 491-502, 1998.

[25] T. L. Saaty, Fundamentals of the Analytic Network Process, ISAHP, Kobe, Japan, 1999.

[26] J. F. Bard, "An efficient point algorithm for a linear two-stage optimization problem," Operations Research, vol. 31, no. 4, pp. 670-684, 1983.

[27] J. F. Bard and J. T. Moore, "A branch and bound algorithm for the bilevel programming problem," SIAM Journal on Scientific and Statistical Computing, vol. 11, no. 2, pp. 281-292, 1990.

[28] W. F. Bialas and M. H. Karwan, "On two-level optimization," IEEE Transactions on Automatic Control, vol. 27, no. 1, pp. 211214, 1982.

[29] W. F. Bialas and M. H. Karwan, "Two-level linear programming," Management Science, vol. 30, no. 8, pp. 1004-1020, 1984.

[30] E. Roghanian, S. J. Sadjadi, and M. B. Aryanezhad, "A probabilistic bi-level linear multi-objective programming problem to supply chain planning," Applied Mathematics and Computation, vol. 188, no. 1, pp. 786-800, 2007.

[31] D. Cao and M. Chen, "Capacitated plant selection in a decentralized manufacturing environment: a bilevel optimization approach," European Journal of Operational Research, vol. 169, no. 1, pp. 97-110, 2006.

[32] J. H. Ryu, V. Dua, and E. N. Pistikopoulos, "A bilevel programming framework for enterprise-wide process networks under uncertainty," Computers and Chemical Engineering, vol. 28, no. 6-7, pp. 1121-1129, 2004. 
[33] J. J. Júdice and A. M. Faustino, "A sequential LCP method for bilevel linear programming," Annals of Operations Research, vol. 34, no. 1-4, pp. 89-106, 1992.

[34] D. J. White and G. Anandalingam, "A penalty function approach for solving bi-level linear programs," Journal of Global Optimization, vol. 35, pp. 1170-1173, 1993.

[35] R. Mathieu, L. Pittard, and G. Anandalingam, "Genetic algorithm based approach to bi-level linear programming," Operations Research, vol. 28, no. 1, pp. 1-21, 1994.

[36] H. Shih, Y. Lai, and E. S. Lee, "Fuzzy approach for multi-level programming problems," Computers and Operations Research, vol. 23, no. 1, pp. 73-91, 1996.

[37] M. Sakawa, I. Nishizaki, and Y. Uemura, "Interactive fuzzy programming for multi-level linear programming problems with fuzzy parameters," Fuzzy Sets and Systems, vol. 109, no. 1, pp. 3-19, 2000.

[38] H. S. Shih and E. S. Lee, "Compensatory fuzzy multiple level decision making," Fuzzy Sets and Systems, vol. 114, no. 1, pp. 71$87,2000$.

[39] X. Shi and H. Xia, "Interactive bilevel multi-objective decision making," Journal of the Operational Research Society, vol. 48, no. 9, pp. 943-949, 1997.

[40] M. S. Osman, M. A. Abo-Sinna, A. H. Amer, and O. Emam, "A multi-level non-linear multi-objective decision-making under fuzziness," Applied Mathematics and Computation, vol. 153, no. 1, pp. 239-252, 2004. 


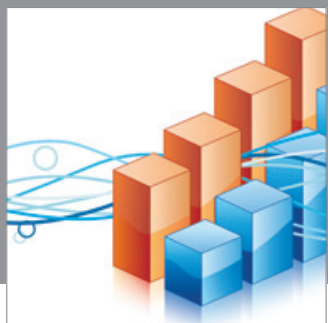

Advances in

Operations Research

mansans

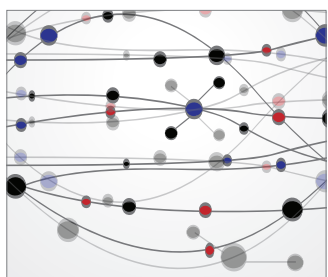

The Scientific World Journal
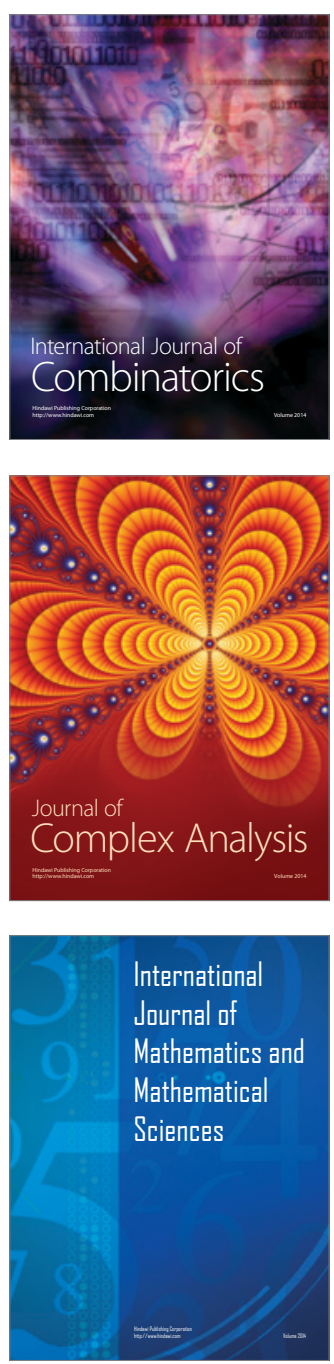
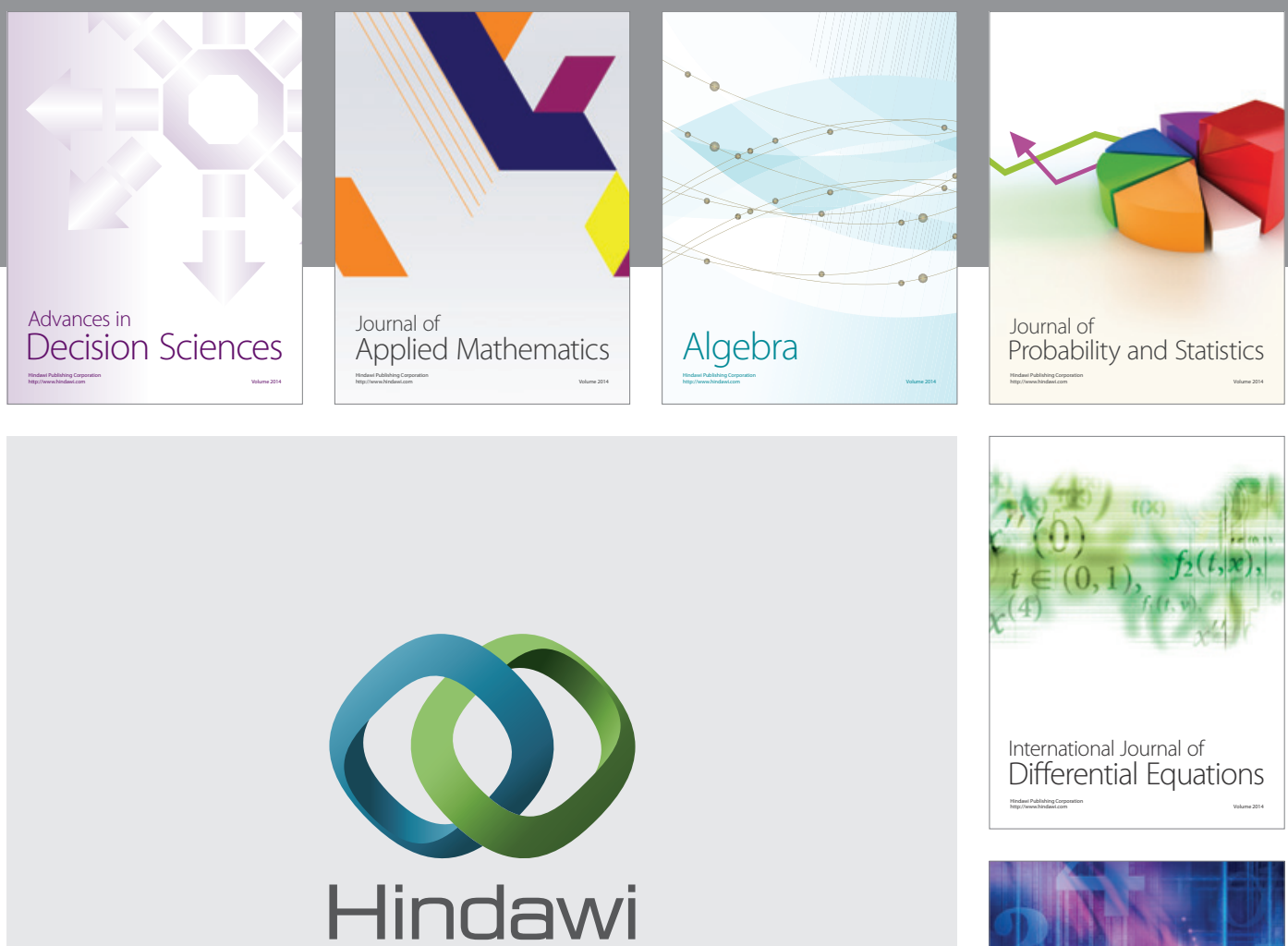

Submit your manuscripts at http://www.hindawi.com
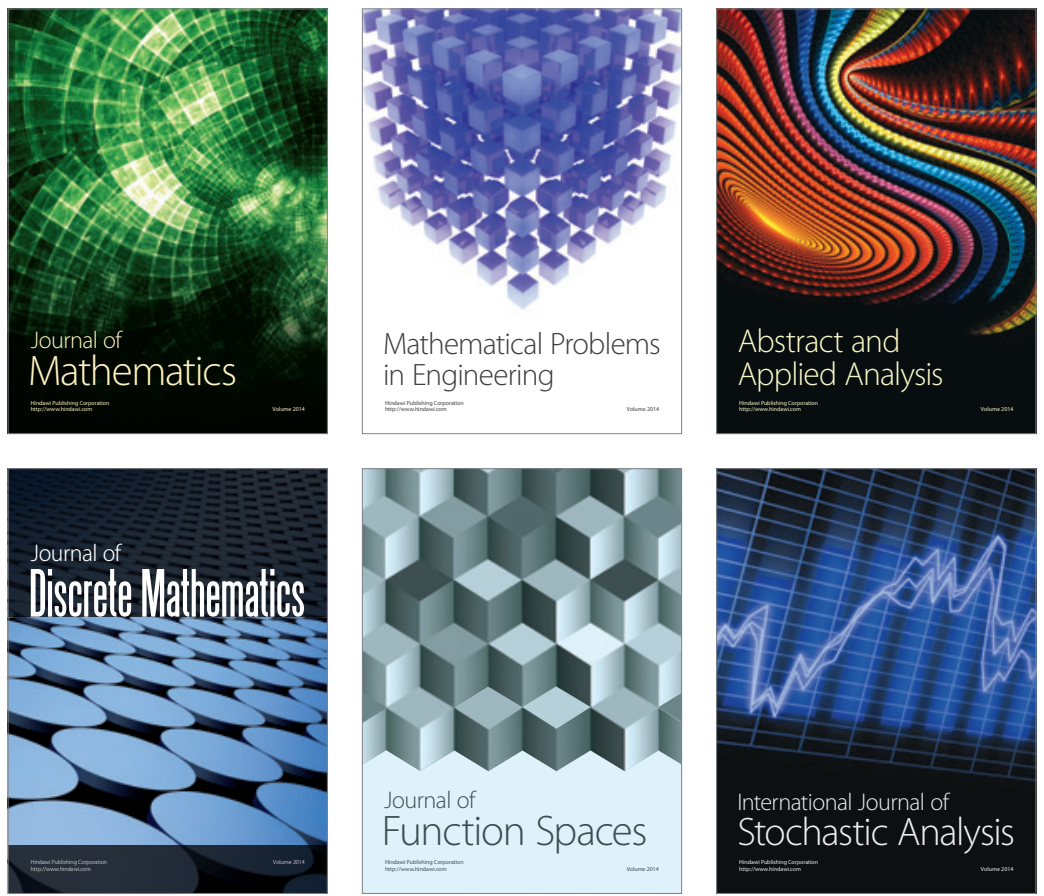

Journal of

Function Spaces

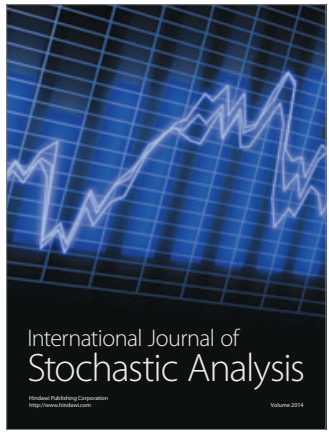

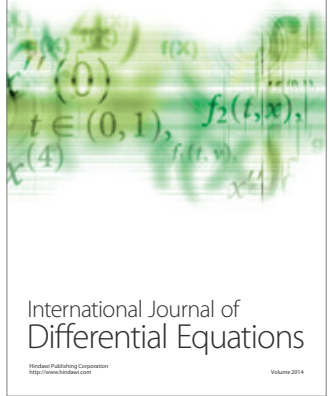
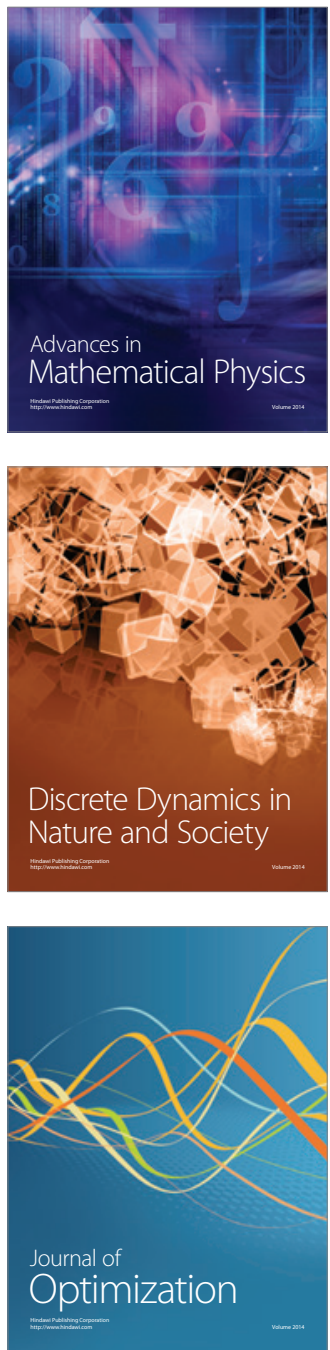